\title{
THE ECOLOGY OF TWO LIZARDS ON A TROPICAL BEACH
}

By

HAROLD FREDERICK HIRTH

\begin{abstract}
A DISSERTATION PRESENTED TO THE GRADUATE COUNCIL OF THE UNIVERSITY OF FLORIDA

IN PARTIAL FULFILLMENT OF THE REQUIREMENTS FOR THE DEGREE OF DOCTOR OF PHILOSOPHY
\end{abstract}

UNIVERSITY OF FLORIDA

June, 1962 


\section{ACKNOWLEDGMENTS}

I wish to express my deepest appreciation to Dr. Archie Carr, Chairman of my Supervisory Comittee, who not only offered help and guidance throughout this period of research, but also provided me with opportunities to study ecological zoogeography in the field.

Many thanks are due Dr. Hugh Popenoe who encouraged my interest in tropical work and was generous with use of books from his personal library.

I wish to thank the other members of my comittee, Drs. Eugene Bovee, Plerce Brodkorb, and Carl Monk, for their suggestions after reading and correcting the original manuscript.

I am indebted to the following people at the University of Florida: Drs. Ernest Ford, Daniel Ward, and Erdman West, who alded in the identification of some herbs and grasses; Dr. John Mullins, who identified a fungus; Dr. Lawrence Hetrick, who rendered invaluable service in the identification of some insects; and Mr. Victor Carlisle, who ident1fled the mineral olivine in my samples of beach sand.

The late Mr. Paul Shank ldentified some of the species of trees on the study area.

I wish to thank the following people for identification of animals: Dr. E. L. Bousfield of the National Museum of 
Canada (amphipods); Dr. D. Johnston of the University of Maryland (mites); and Dr. M. L. Wass of the Virginia Fisheries Laboratory (crabs).

I wish to acknowledge the help and companionship of Larry ogren and Chuck Carr on many field trips at Tortuguero.

Special gratitude is due Miss Lois White, who typed the preliminary drafts of the dissertation and who gave me moral support throughout the study.

This research was aided by fellowships from the college of Arts and Sciences, University of Florida; National Science Foundation; and the Society of the Sigma Xi.

Fleld work at Tortuguero was indirectly supported by assistantships from the Graduate School, University of Florida; by the Caribbean Conservation Corporation; and by grants (G- 1684, G- 5479, and G- 10717; The Ecology and M1grations of Sea Turtles; Dr. Archle Carr, Principal Investigator) from the National science Foundation. 
TABLE OF CONTENTS

Page

ACKNOWLEDGMENTS

LIST OF TABLES

vi

LIST OF ILLUSTRATIONS

vii

INTRODUCTION

METHODS OF STUDY

THE PHYSICAL ENVIRONMENT . . . . . . . . . . 8

Physical Aspects of the Beach ......... . 8

Sand................ . . 9

Sand temperatures ............ 13

Climate ................ 15

Rainfali . . . . . . . . . . 15

Temperature ............. . . 19

Vapor pressure deficit . . . . . . . . 22

Llght . . . . . . . . . . . . . 23

vegetation .............. . . 23

Events after clearing .. . . . . . . 28

THE LIZARDS: GENERAL FEATURES, RANGE, AND HABITAT

PREFERENCES .................. 29

The Lizards . . . . . . . . . . . . . 29

Habltat Preferences ............. 30

ACTIVITY OF THE LIZARDS . . . . . . . . . . . 32

Diurnal Activity . . . . . . . . . . 32

Nocturnal Activity ............ . . 36

THERMOREGULATION . . . . . . . . . . . . 40

Temperature Preferences ............ 42

Behavior at High Temperatures ......... 49

Nocturnal Temperature ............ 53

Reflectivity of Integuments . . . . . . . . 54

Internal Pigmentation . . . . . . . . . . 57 
Page

FOOD

Size of Prey ................. 69

Feeding Behavior ............ 71

MOVEMENTS

Methods of study .............. 75

Size of Home Range ............. 76

Center of Activity . . . . . . . . . . 82

GROWTH AND LONGEVITY ............. . . 85

ontogenetic Changes in Length of Tail..... 87

REPRODUCTION . . . . . . . . . . . . . 90

Size at sexual Maturity ... . . . . . . . 90

The Breeding Season............... 91

Courtship and Mating Behavior... . . . . . . 91

Nesting Locality . . . . . . . . . . 94

PARASITES AND PREDATORS . . . . . . . . . . . 96

STRUCTURE OF THE POPULATIONS . . . . . . . . . . 98

Density . . . . . . . . . . . . . 98

Sex Ratios ................ 102

Replacement of the populations ....... 103

LOCOMOTION . . . . . . . . . . . . . 106

swimming .................. 108

AGGREGATION . . . . . . . . . . . . . . . 110

SUCCESSION IN LIZARD POPULATIONS . . . . . . . . . 114

OTHER ANIMALS ON THE BEACH: THE BEACH AS AN ECOTONE - 117

DISCUSSION . . . . . . . . . . . . . 122

SUMMARY AND CONCLUSIONS . . . . . . . . . 129

LITERATURE CITED . . . . . . . . . . . . . 134

BIOGRAPHICAL SKETCH . . . . . . . . . . . 143 


\section{LIST OF TABLES}

Table

Page

1. Analysis of sand on the strand . . . . . . . . 11

2. Diel maximum and minimum sand temperatures (in ${ }^{\circ} \mathrm{C}$ ) during the two wet and dry seasons at Tortuguero 14

3. Rainfall (in inches) in the summer months . . . 19

4. Vegetation in the three major habitats on the strand ................ . . 24

5. Some important thermal thresholds and limits for Ameiva and Basiliscus . . . . . . . . . . 48

6. Stomach contents of Ameiva and Basiliscus in the rainy season ........... . 60

7. Home ranges of Ameiva guadrilineata . . . . . 77

8. Home ranges of Basiliscus vittatus . . . . . 78

9. Growth rates of Ameiva . . . . . . . . . . 85

10. Growth rates of Basiliscus . . . . . . . . . 86

11. Numbers of Ameiva on 8.5 acres at different periods ....................... 99

12. Numbers of Basiliscus on 8.5 acres at different periods ...... . . . . . . . . 100

13. Spatial distribution of $\underline{A}$. quadrilineata and juvenile B. vittatus on the beach at three different times............... . . 111

14. Aggregations of Ameiva and juvenile Basiliscus on and around the same log at the same time . . 113 


\section{LIST OF ILLUSTRATIONS}

Figure

Page

1. Sketch map of the strand at Tortuguero, Costa Rica................... 2

2. Number of degrees between diel maximum and minimum sand temperatures at various depths . . . 16

3. Rainfall at Tortuguero, Costa Rica, from June, 1960, to May, 1961 . . . . . . . . . 18

4. Maximum and minimum air temperatures and vapor pressure deficit on the strand at Tortuguero.

5. Relative numbers of Ameiva and Basiliscus seen on 8.5 acres of beach under "clear" and "cloudy" conditions................

6. Body temperatures of lizards (Amelva), substrate temperatures, and air temperatures taken between 0600 and 1200 hours . . . . . . .

7. Body temperatures of lizards (juvenile Basiliscus), substrate temperatures, and air temperatures taken between 0600 and 1200 hours . . .

8. Body temperatures of lizards (adult Basiliscus). substrate temperatures, and air temperatures taken between 0600 and 1200 hours . . . . 46

9. Isothermal plots of body temperatures and air temperatures of 27 adult basilisks captured at night between 1800 and 0500 hours . . . .

10. Size-frequency distribution of food items eaten by juvenile and adult Basiliscus . . . . . 70

11. Relative tail lengths in lizards of different sizes

12. Changes in populations of lizards during the clearing, habitation, and abandonment of a homesite on the riverbank .......... 115 


\section{INTRODUCTION}

This study concerns the ecology of Ameiva quadrilineata Hallowell (Teildae) and Basiliscus vittatus Wiegmann (Iguanidae). Both animals are particularly abundant on the beach at Tortuguero in LImón Province on the Caribbean coast of Costa Rica, at lat. $10^{\circ} 34^{\prime} \mathrm{N}$. long. $83^{\circ} 32^{\prime} \mathrm{W}$. The village of Tortuguero is situated on the strand between the Caribbean sea and the Tortuguero River. This study was made on a two-mile section of the beach between the village and the mouth of the river (Fig. 1).

Little work has been done on either the ecology or taxonomy of Costa Rican lizards since the publication of Taylor's handbook (1956), in which elght families and 25 genera of lizards known to occur in Costa Rica are treated.

Descriptions of the region can be found in the accounts of the sea turtle research of Carr and ogren (1960) and Carr and Hirth (1962). Caldwell, Ogren, and Giovannoli (1959) described some fishes from the vicinity of Tortuguero; and slud (1960) studied the avifauna in the tropical wet forest approximately 35 miles inland from Tortuguero. References to ecological work on marine beaches in other parts of the tropics can be found in Hedgpeth (1957) and Neill (1958).

A total of 310 days was spent at Tortuguero. Collections and observations were made in eight different months, 


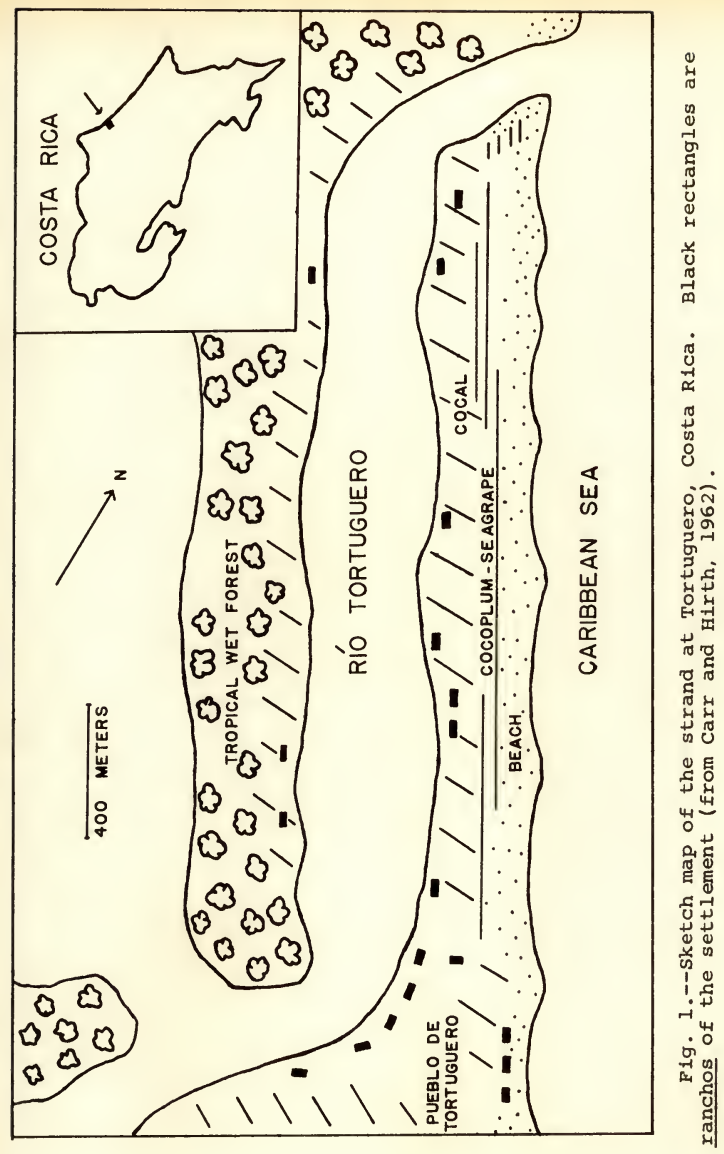


in both wet and ary seasons. Actual time spent at the study area was as follows: June 6-september 18, 1959; January 26February 4, 1960; June 9-September 14, 1960; March 20-April 3, 1961; and July 11-september 30, 1961

Because temperature is perhaps the most important $1 \mathrm{im}-$ 1ting factor in the ecology of an ectotherm, special emphasis in this study has been placed on temperature, both that of the lizards and that of the physical environment.

The role of thermoregulation in the ecology of ectotherms has attracted considerable interest since the work of Cowles and Bogert (1944). Most of the research has been done in the temperate zone (see Cowles and Bogert 1944, and Bogert 1949a, for a review of the literature). Only within the last few years, however, has thermoregulation in tropical lizards been investigated. Bogert (1949b) studied thermoregulation in several species of sceloporus in Mexico and Honduras. Inger (1959) investigated temperature preferences of Mabuya rudis and sphenomorphus sabanus in Borneo. Ruibal (1961) determined thermal tolerances of five species of Anolis in Cuba. W1lhoft (1961) studied temperature responses

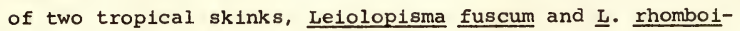
dalis, in Australia. It has been the general conclusion of these workers that selection of habitat, behavior, and thermal sensitivity are closely interrelated.

The various thermal thresholds of Ameiva quadrilineata and Basiliscus vittatus are discussed in this paper. Temperature data for two other lizards in the area, Amelva festiva Lichtenstein and von Martens and Basiliscus plumifrons Cope, 
and some for Ameiva pluvianotata Garman from the island of Montserrat, B.W.I., have been included as a basis for a comparison of preferred temperatures of congeners in different, and in similar, habitats.

This study seemed particularly inviting because preliminary observations on the beach at Tortuguero indicated that Ameiva and juvenile Basiliscus occupy closely similar ecological niches. Three years of subsequent study have borne out this initial impression and at the same time have shown that the situation does not constitute an exception to Gause's rule.

The aims of the study can be summarized as an analysis of environmental and behavioral factors affecting the ecological distribution of and population dynamics of Ameiva quadrilineata and Basiliscus vittatus on a tropical beach. 


\section{METHODS OF STUDY}

All data for weather were collected with standard meteorological instruments placed at a height of five feet. Two weather stations 250 feet apart, one on the beach and the other in the coconut grove (cocal), were operated concurrently through the summer months. Maximum and minimum air temperatures and wet and dry bulb readings were taken twice each day at both stations. Rainfall was collected at the beach station. While I was present at the study area the rainfall was collected during 12-hour perlods, which approxImated the length of day and night. At other times a local helper recorded the daily rainfall.

Lizards were collected by shooting, noosing, trapping, and hand-collecting. A few were obtained by means of a blowgun and slingshot. Various types of funnel and pitfall traps (Vogt 1941, Fitch 1951, Banta 1957) were made and used with varying success. Adult basilisks were most frequently caught by noosing.

All lizards were either marked and released at the spot of capture or preserved in formalin and dissected in the laboratory at the University of Florida. Lizards were individually marked by toe clipping. In addition, a piece of blue string was tied around the abdomen of males and red string around females. This proved useful in making 
observations of social relationships, especially among the juveniles. It also provided a means of making a rough estimate of the numbers of marked individuals without the necessity of re-catching them. When each lizard was marked for release it was assigned a number, and the following information was recorded: species, sex, time, date, snout-vent length, total length, body temperature, air temperature, substrate temperature, presence and location of ectoparasites, stage of molting, exact position in the habitat, amount of cloud-cover, and type of clouds.

All measurements of each lizard were recorded to the nearest millimeter. Snout-vent $(s-v)$ length is measured from the tip of the snout to the anterior margin of the anus. Total length is measured from the tip of the snout to the tip of the tall. All temperatures were taken with a schultheis quick-recording thermometer. Cloud-cover was recorded to the nearest tenth, in the manner outlined by Haynes (1947).

Recovery of marked lizards provided information on growth, longevity, population density, and home ranges. Dissection provided data on food habits, size at sexual maturity, and a means of verifying the sex of juveniles.

A combination of criteria was used for determining sex in the field. In the case of Ameiva, if a pair of large postanal scales was present or the venter was tinted with bluish-green, or both, the individual was considered to be a male. In case of doubt, especially with juveniles, the sex was determined by applying gentle pressure to the base of 
the tail to evert the hemipenis. The sex of very small individuals could not be determined; but in a few cases these lizards were recaptured later, after maturing, and field records were adjusted accordingly.

Among adult basilisks, the sexes are easily distinguished by the relative size of the dorsal crest and by color patterns. Sex was determined in the juvenile basilisks on the basis of color patterns and of the degree of keeling of the ventral scales, which usually is stronger in the females. As with Ameiva, attempts were made to evert the hemipenis in questionable males. The sex of very small juveniles could not be determined at all.

An insect collection was made, and the major families were identified with the help of entomologists at the University of Florida. This collection provided a basis for the identification of stomach contents.

Juvenile and adult basilisks are here treated as separate populations because they occupy different habitats. The word juvenile refers to any lizard below the size of sexual mature individuals. Due to the lack of an accepted common name for Ameiva, the term "beach lizard," or the anglicized family designation, "teild," will be used for Ameiva in this report.

Statistical equations, procedures, and tables were taken from Pearson (1914), Hald (1952), and Waugh (1952). When not specified, statistical significance is set at the 1 per cent level. The standard error of the mean is given in parentheses after the mean.

The 24-hour time system is used throughout this report. 
THE PHYSICAL ENVIRONMENT

\section{Physical Aspects of the Beach}

The shoreline at Tortuguero is an irregular series of trlangular cusps with concave sides and rounded apices. A suite of the cusps was measured along the study area in March, 1961. The lengths at the bases varied between 100 and 300 feet, and the distances from bases to apices were from 60 to 120 feet. The greatest elevation of the cusp above sea level, at the baseline, was usually about two feet. Distances between apices ranged from 300 to 900 feet. These dimensions are probably reduced in the rainy seasons. The chief physical factor in cusp formation along seashores is the parallel advance of waves along the coast (Johnson 1919). The configuration of the beach changes from year to year. For example, in June, 1959, there was a prominent cusp in front of the research camp. In september of the same year it was half gone, and by June, 1960, it was completely gone; but another cusp was forming just to the south. In March, 1961, this new cusp was very prominent; but by september, 1961, 1t had eroded away. The longshore current, along with seasonal varlations in flow from the Tortuguero River combined with tidal action, may be responsible for these changes. 
Since the lizards make frequent forays to the edge of the water to feed among the tidal wrack, the configuration of the coast affects the size of the home range of the lizard.

Seasonal records of salinity were not kept. The salin1ty of the sea, measured by hydrometer, was $26.5 \%$ on september 15, 1960, and $36.7 \%$ on March 31, 1961. The salin1ties in the Tortuguero River, two miles from the mouth, taken the same days as above, were $2.0 \%$ and $2.6 \%$.

The beach is littered with a variety of debris, principally logs (Carapa sp.) that have drifted away from booms in the Tortuguero River. The tidal wrack is composed chiefly of hyacinth (Eichhornis crassipes), called locally choreja. This is especially abundant in the rainy season. Large rafts of choreja are frequently seen drifting down the river and in the sea after heavy rains.

There are very few stones, pebbles, or shells on the strand. The largest rock found was a plece of pumice $6 " \times 4 " \times 3 / 4 "$. The beach is littered with seeds, the most common of which is the sea bean (Macuna sloan1i).

\section{Sand}

Soll samples were obtained by digging three lines of holes, with eight holes in each line, in each major vegetation zone. Soll samples were then taken from depths of 0-2", 2-8", and 8-16". Each sample analyzed was a composite from 24 holes. Soil samples were also taken from a series of elght holes in one line on the top of the wave-cut bank on 
the shore. Soll color, $\mathrm{pH}$, salt concentration, and particle size were examined, and the results are shown in Table 1.

Soll colors are taken from the Munsell soll Color Charts, 1954 edition. In this system, hue, value, and chroma are combined to describe colors. The hue indicates the dominant spectral color; value indicates lightness; and chroma, the relative purity or strength of the spectral color. The figures given in Table 1 are for hue, value, and chroma, in that order. Colors were obtained both from air-dry soil and samples moistened to field capacity. The predominant sollsurface colors throughout the strand range from olive-gray to very dark gray-brown when dry, and from dark olive-gray to black when wet. The black aspect of the beach is materially enhanced by precipitation. Value and chroma at the surface level darkened up to one and two steps respectively when the soil was wet to field capacity.

Soll-pH was determined with the Beckman $\mathrm{pH}$ meter and water soluble salts were analyzed by means of a solu-bridge and conductivity cell at $25^{\circ} \mathrm{C}$. The electrical conductance of the saturation extract was calculated in millimhos/centimeter. When interpreted by means of salinity scales soils at all depths and in all areas fall into the non-saline category. This is interesting because the study area is constantly under the influence of salt spray. It is probably due to a high degree of leaching. Work in other areas has shown that many coastal dunes contain low concentrations of dissolved salts (for review of literature see Boyce 1954). 
TABLE 1.--Analysis of sand on the strand.

\begin{tabular}{|c|c|c|c|c|c|}
\hline \multirow{2}{*}{ Area } & \multirow{2}{*}{$\begin{array}{l}\text { Depth } \\
\text { in } \\
\text { inches }\end{array}$} & \multicolumn{2}{|c|}{ Color } & \multirow{2}{*}{ pH. } & \multirow{2}{*}{$\begin{array}{l}\text { Conduct- } \\
\text { ance in } \\
\text { millilm- } \\
\text { hos } / \mathrm{cm} \text {. }\end{array}$} \\
\hline & & Dry & Wet & & \\
\hline $\begin{array}{l}\text { Fore- } \\
\text { beach }\end{array}$ & $\begin{array}{l}0-2 \\
2-8 \\
8-16\end{array}$ & $\begin{array}{ll}2.5 Y & 4 / 2 \\
2.5 Y & 4 / 0 \\
2.5 Y & 4 / 2\end{array}$ & $\begin{array}{ll}2.5 \mathrm{Y} & 3 / 0 \\
2.5 \mathrm{Y} & 3 / 0 \\
2.5 \mathrm{Y} & 3 / 0\end{array}$ & $\begin{array}{l}7.2 \\
8.2 \\
8.9\end{array}$ & $\begin{array}{l}0.31 \\
0.45 \\
0.38\end{array}$ \\
\hline Beach & $\begin{array}{l}0-2 \\
2-8 \\
8-16\end{array}$ & $\begin{array}{rr}5 \mathrm{Y} & 4 / 2 \\
2.5 \mathrm{Y} & 3 / 2 \\
2.5 \mathrm{Y} & 3 / 2\end{array}$ & $\begin{array}{rr}5 \mathrm{Y} & 3 / 2 \\
2.5 \mathrm{Y} & 2 / 0 \\
2.5 \mathrm{Y} & 3 / 0\end{array}$ & $\begin{array}{l}6.9 \\
6.5 \\
6.7\end{array}$ & $\begin{array}{l}0.15 \\
0.24 \\
0.15\end{array}$ \\
\hline $\begin{array}{l}\text { Cocoplum- } \\
\text { seagrape }\end{array}$ & $\begin{array}{l}0-2 \\
2-8 \\
8-16\end{array}$ & $\begin{array}{ll}\text { lOYR } & 3 / 2 \\
\text { lOYR } & 3 / 2 \\
\text { lOYR } & 4 / 1\end{array}$ & $\begin{array}{ll}\text { lOYR } & 3 / 2 \\
\text { lOYR } & 2 / 2 \\
\text { lOYR } & 2 / 1\end{array}$ & $\begin{array}{l}6.2 \\
6.6 \\
6.4\end{array}$ & $\begin{array}{l}0.25 \\
0.24 \\
0.30\end{array}$ \\
\hline $\begin{array}{l}\text { Coconut } \\
\text { grove }\end{array}$ & $\begin{array}{l}0-2 \\
2-8 \\
8-16\end{array}$ & $\begin{array}{ll}2.5 Y & 3 / 2 \\
2.5 Y & 4 / 2 \\
2.5 Y & 4 / 2\end{array}$ & $\begin{array}{ll}2.5 \mathrm{Y} & 2 / 0 \\
2.5 \mathrm{Y} & 3 / 2 \\
2.5 \mathrm{Y} & 3 / 0\end{array}$ & $\begin{array}{l}6.1 \\
6.0 \\
6.5\end{array}$ & $\begin{array}{l}0.34 \\
0.55 \\
0.40\end{array}$ \\
\hline
\end{tabular}


TABLE 1--Extension

Per cent particle size in millimeters

\begin{tabular}{llllll}
$>1.0$ & $1.0-.5$ & $.5-.25$ & $.25-.10$ & $.10-.05$ & $<.05$ \\
\hline 0.0 & 0.1 & 12.9 & 80.0 & 7.0 & 0.0 \\
0.0 & 2.0 & 34.0 & 62.0 & 2.0 & 0.0 \\
0.0 & 7.5 & 45.9 & 46.5 & 0.1 & 0.0 \\
0.0 & 2.0 & 28.5 & 65.5 & 3.9 & 0.1 \\
0.0 & 1.0 & 24.0 & 71.0 & 3.9 & 0.1 \\
0.0 & 1.9 & 32.1 & 65.0 & 1.0 & 0.0 \\
0.5 & 3.0 & 34.5 & 60.0 & 1.7 & 0.3 \\
0.0 & 0.8 & 23.2 & 74.4 & 1.5 & 0.1 \\
0.0 & 0.3 & 20.0 & 78.0 & 1.6 & 0.1 \\
0.2 & 6.0 & 22.0 & 62.0 & 9.4 & 0.4 \\
0.5 & 6.5 & 25.0 & 62.5 & 5.1 & 0.4 \\
0.2 & 5.7 & 20.0 & 65.0 & 9.0 & 0.1
\end{tabular}


Particle-size distribution was determined by mechanical analysis, using standard soll sieves. No particles over $1.0 \mathrm{~mm}$ were found anywhere on the beach. Particles less than $0.05 \mathrm{~mm}$ were found in all habitats except the shoreline. The predominant soll particle size in all areas and at all depths was the 0.25-0.10 size-class. The majority of soll in all habitats can be described as fine to medium sand.

The most abundant mineral in the sands is a highly ferruginous variety of olivine. This is largely responsible for the olive-gray color of the sand when dry. Very small amounts of silica are also present.

The majority of lizards are active on the beach and in other areas when the sand is dry. The particle size seems to have no adverse influence on the "grubbing" habits of Ameiva (see section: Feeding Behavior).

Sand temperatures. Diel change in sand temperatures on the beach was determined with slow-reading mercurlal thermometers accurate to the nearest $0.1^{\circ} \mathrm{C}$. The thermometers were lowered to various depths through bamboo tubes. The temperatures were taken every hour on four different days.

Table 2 shows maximum and minimum sand temperatures at six depths in the wet and dry seasons. The March and September records were taken during dry periods. On January 29 one inch of rain fell, and on July 19 there was a half-inch. The data 1ndicate that sand temperatures at each depth do not vary significantly throughout the year. The beach lizards are, of course, in direct contact with the surface and probably come into contact with sand at temperatures of the 


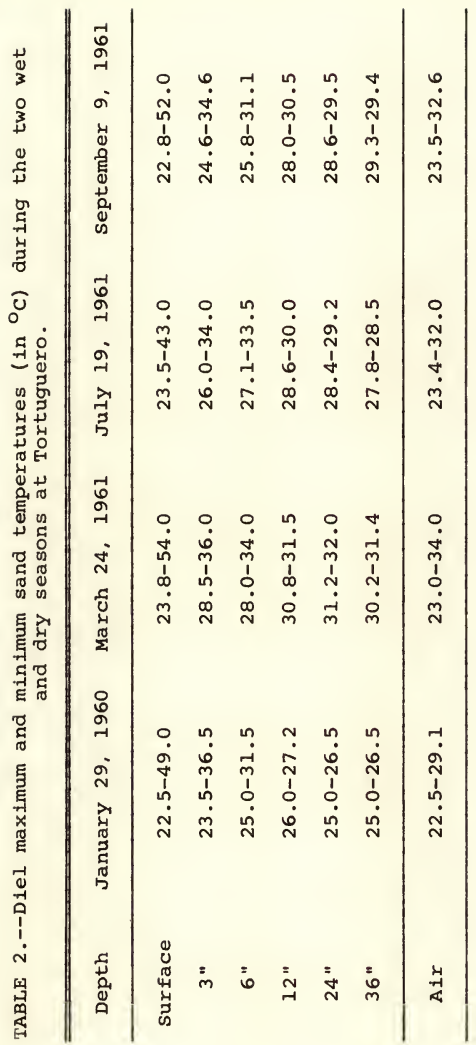


three-inch and six-inch levels when digging nests. Some telids have been observed "squirming" in the sand, evidently in order to expose more body surface to the hot sand and thus raise their own body temperature. As Carr and ogren (1960) pointed out, energy absorption is higher in the black sand at Tortuguero than in 11ght-colored beach sand. This was borne out by observations made one morning when the sand surface temperature rose from $28.5^{\circ} \mathrm{C}$ at 0900 hours to $44.0^{\circ} \mathrm{C}$ after one hour of sun. This phenomenon is important for the ectothermic lizards whose activity periods are sometimes confined to short, sunny perlods between rain storms. The highest surface temperature recorded was $73.0^{\circ} \mathrm{C}$ at 1300 hours on September 8, 1960.

F1g. 2 shows the difference between the maximum and minimum temperatures for each of the four days. As might be expected, there is a large range in temperatures at the surface, but only small fluctuations below 12 inches.

\section{Climate}

There are approximately 12.5 hours of light and 11.5 hours of darkness each day at Tortuguero. The study area constantly recelves salt spray. Most of the rain comes from a northeasterly direction. Nimbostratus, or low water clouds, are the formations which bring most of the precipitation to the study area. Cumulus clouds are common on sunny days.

Rainfall. In the tropics, seasonal variation in rainfall is much more important than seasonal changes in temperature. A record of rainfall was kept for one year, from 


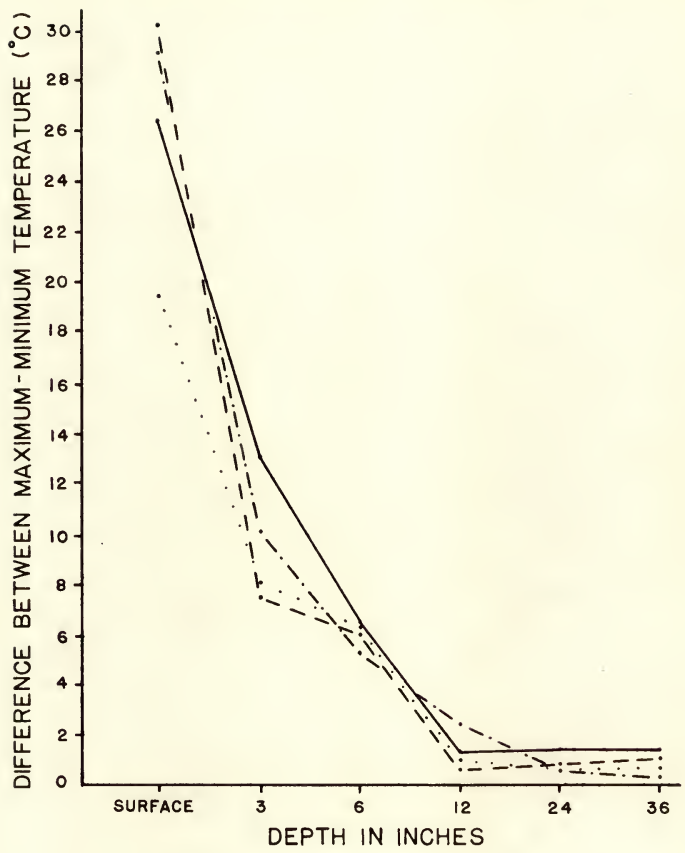

Fig. 2.--Number of degrees between diel maximum and minimum sand temperatures at various depths. Solid line represents temperatures on January 29; dashed line is March 24; dotted line is July 19; and dot-dash line is september 9 . 
June, 1960, through May, 1961 (F1g. 3). During this period a total of 155.30 inches $(3,882.5 \mathrm{~mm})$ of rain fell at Tortuguero. It may be seen that there are two distinct rainy seasons, separated by fairly dry periods. The data indicate that 59.1 per cent of the total annual rainfall fell in the four months of July, August, December, and January. In no month was there less than two inches of rain. At least 0.1 inch of rain was recorded on 169 days of the year. According to local inhabitants, this was a typical pattern and amount of rain.

Leon (1952) stated that there is a decreasing amount of rainfall on the Caribbean coast of costa Rica from north to south. The area between San Juan del Norte, Nicaragua, and Boca del Colorado, Costa Rica, has an annual rainfall of about 6,400 mm. Puerto Limón, Costa Rica, recelves approximately 2, 224-3, $234 \mathrm{~mm}$. The precipitation at Tortuguero is, as would be expected from its location 26 miles south of Boca del Colorado and 50 miles north of Puerto Limón, intermediate.

Additional rainfall data are avallable for June, July, August, and september over a three-year period (Table 3 ). over this perlod, an average of 8.76 inches of rain fell at night ( 1800 hours to 0600 hours) each month and 7.41 inches during the day. Although more rain was collected at night, the deviation from an expected 50:50 night-day rainfall is not statistically significant. 


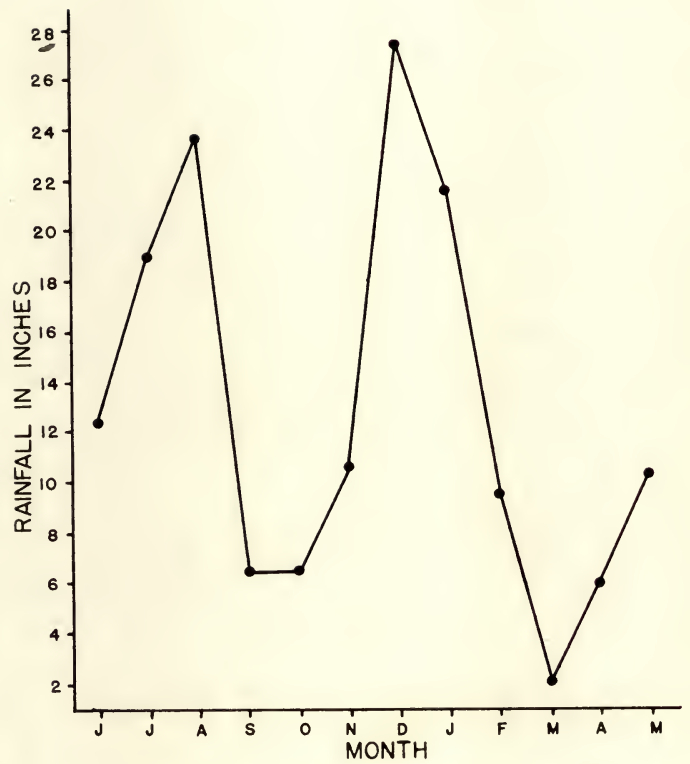

Fig. 3.--Rainfall at Tortuguero, Costa Rica, from June, 1960, to May, 1961. 
TABLE 3.--Rainfall (in inches) in the summer months.

\begin{tabular}{lrrrr}
\hline \multirow{2}{*}{ Month } & \multicolumn{3}{c}{ Year } & \\
& 1959 & 1960 & 1961 & Mean \\
\hline June 11-30 & 13.48 & 12.25 & -- & 12.87 \\
July 1-31 & 26.42 & 19.10 & 12.90 & 19.47 \\
August 1-31 & 15.55 & 23.80 & 32.90 & 24.08 \\
September 1-15 & 5.85 & 6.35 & 12.85 & 8.35 \\
\hline
\end{tabular}

The longest period of rain recorded was in 1959, when from June 21 to July 26 at least 0.1 inch of rain was recorded in every 24-hour period. The heaviest 12-hour rainfall was on July 8, 1959, when 4.10 inches fell during the night. The heaviest 24 -hour precipitation was 5.20 inches on August 8, 1960. The most intense precipitation occurred on August 8, 1960. During a two-hour period 3.10 inches of rain fell. This was followed by 3.40 inches of rain in 3.5 hours on June 23, 1960, and 1.1 inches in two hours on August 2, 1961. During periods of such intense rain all 11zards stay under cover.

Temperature. The Atlantic coast of costa Rica was generally classed as tierra caliente (hot zone) by sapper (1932). This zone is characterized by having an annual mean temperature of $23-26^{\circ} \mathrm{C}$. On the ecological map of costa Rica prepared by Holdridge (1959) the area inland from Tortuguero is described as a Bosque Troplcal Muy Húmedo (very wet tropical forest) with a mean annual temperature of at least $24.0^{\circ} \mathrm{C}$. 
The mean annual temperature at Tortuguero can be est1mated by using the criteria of Mohr and Van Baren (1954). As a result of their work in tropical solls they found that the mean temperature of the soll from the surface to a depth of at least $110 \mathrm{~cm}$ exceeds that of the atmosphere by about $3.4^{\circ} \mathrm{C}$. Diel sand temperatures were taken four times during the wet and dry seasons (Table 2 and Fig. 2), and the mean temperature at a depth of 36 inches was $28.4^{\circ} \mathrm{C}$. This would Indicate a mean air temperature of $25.0^{\circ} \mathrm{C}$. However, the study area at Tortuguero is also under maritime influences, which have an effect upon the dally and seasonal temperature.

Maximum and minimum temperatures were taken at 0600 hours and 1800 hours on both the beach and in the coconut grove from June 10 to September 15. Temperatures were also taken for an elght-day perlod from January 27 to February 3, and for the twelve days from March 22 to April 2.

The two-year maximum and minimum averages for the four summer months are given in Fig. 4. The figure shows that the temperatures vary less in the cocal and that minimum temperatures on the beach are fairly constant. The average maximum and minimum temperatures on the beach during the January-February period were $28.2^{\circ} \mathrm{C}$ and $19.2^{\circ} \mathrm{C}$ respectively. During March and April the days are warmer and the high and low for a typical day are $31.3^{\circ} \mathrm{C}$ and $25.5^{\circ} \mathrm{C}$.

The highest air temperature recorded on the beach was $37.8^{\circ} \mathrm{C}$, and the next highest was $35.6^{\circ} \mathrm{C}$. Both were taken in september, 1959. The highest night temperature found was $30.0^{\circ} \mathrm{C}$ on June 20,1960 . The lowest day and night 


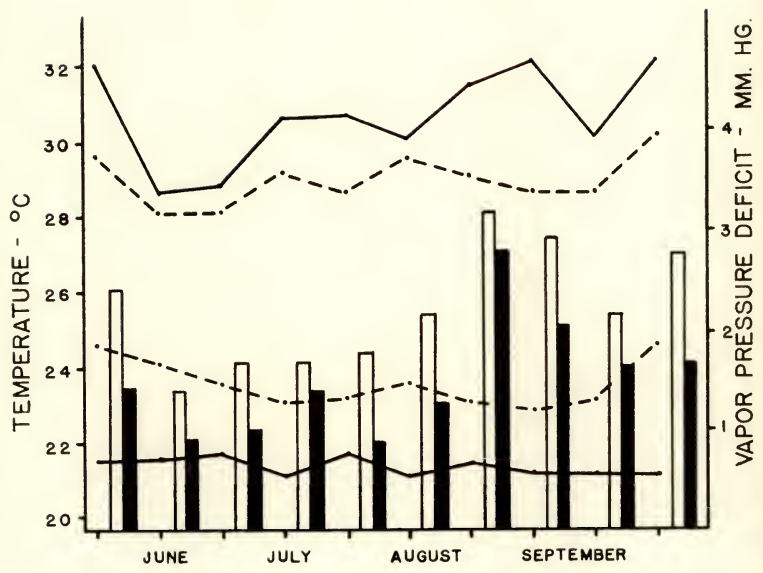

Fig. 4.--Maximum and minimum air temperatures and vapor pressure deficit on the strand at Tortuguero. Values are the ten-day averages of two years from June 10 to september 15. Solld lines represent temperatures on the beach, and dashed lines represent those in the cocal. White bars indicate vapor pressure deficit between 0700-0800 hours on the beach, and black bars denote v.p.d. in the cocal. 
temperatures were $18.3^{\circ} \mathrm{C}$ and $17.5^{\circ} \mathrm{C}$, respectively. The highest temperature recorded in the coconut grove was $33.0^{\circ} \mathrm{C}$, and the lowest was $21.0^{\circ} \mathrm{C}$.

Combining data from all collecting periods, the average maximum and minimum day temperatures on the beach are $30.5^{\circ} \mathrm{C}$ and $22.0^{\circ} \mathrm{C}$, respectively. The night temperatures are between $26.2^{\circ} \mathrm{C}$ and $21.0^{\circ} \mathrm{C}$. In the cocal the average maximum and minimum day temperatures are $29.0^{\circ} \mathrm{C}$ and $24.0^{\circ} \mathrm{C}$, and the night temperatures are between $26.5^{\circ} \mathrm{C}$ and $23.5^{\circ} \mathrm{C}$.

Vapor pressure deficit. Wet and dry bulb temperatures were taken with a sling-psychrometer, on the beach and in the coconut grove, between 0700 and 0800 hours. This is the time of the day when lizards start to become active in both habitats. The vapor pressure deficit (v.p.d.) was computed from these readings (Fig. 4). The results indicate that v.p.d. on the beach is always between 1.4 and $3.2 \mathrm{~mm}$ of $\mathrm{Hg}$. The saturation deficit in the coconut grove is always lower. The v.p.d. was also taken between 1500 and 1600 hours, when some lizards are on the beach for a second, shorter period of activity. The average monthly readings for June 10 to september 15 on the beach are as follows: June, 4.8; July, 3.9; August, 4.2; and September, $6.3 \mathrm{~mm} \mathrm{Hg}$. The averages for the same months in the coconut grove are 3.7, 2.7, 3.7 , and $4.8 \mathrm{~mm} \mathrm{Hg}$. Saturation deficit is higher in both habitats in the afternoon.

A v.p.d. of $12.4 \mathrm{~mm} \mathrm{Hg}$. (61 per cent relative humidity) was the maximum ever recorded on any one day in both areas. 
Light. The amount of solar radiation available for thermoregulation in each plant zone was measured with a General Electric light-meter, calibrated in foot-candles. Fifty readings, five feet apart, were taken on the ground along a transect extending across the strand. The measurements were made on March 24, 1961, under a cloudless sky, between 1130 and 1230 hours. The photosensitive element was pointed straight up. Mean light intensity in foot-candles was as follows (range indicated in parentheses): beach, 8, 300 $(6,000-9,500)$; cocoplum-seagrape hedge, 2, 400 (500-6,000); and coconut grove, $1,200(400-3,000)$. The light intensity at a height of five feet (just above the shrub layer) was also computed in the coconut grove. The result was 3,100 (500-8,000) foot-candles. The amount of sunlight reaching the substrate in the cocal is especially important for Amelva, which rarely climbs. The basilisks have favorite elevated basking sites, and the sunlight above the shrub layer is more important for them.

\section{Vegetation}

To determine the plant composition a series of ten transects was run across a typical segment of the strand. The lines were 200 feet apart and varied from 400 to 800 feet in length. Numerical abundance, frequency, and cover were recorded for each species in each habitat. Basal area was computed for trees. Percentage numerical abundance was obtained by dividing the number of plants of each species by the total number of all plants in each area. In the case of 
grasses, each item bearing a flowering head constituted an individual. With low shrubs, each crown constituted one individual. Frequency was obtained by noting the percentage of the ten transects in which a given specles occurred. Percentage of cover was determined by dividing the amount of cover each species contributed to the transects by the total amount of plant-cover. All individuals were counted, regardless of whether the stem was on the transect. Cover of grasses and low herbs was measured at the ground surface, while cover for shrubs and trees was measured by the crownspread intercept. The diameter at breast helght was determined for all tree species and from these measurements basal area was obtained from appropriate tables.

There are three major vegetated habitats on the strand-the beach, a hedge row of salt-resistant plants, and a coconut grove. The vegetation in each habitat is given in Table 4. Names of herbaceous plants and ferns are from Small (1933, 1938) and P1ttier (1957). Nomenclature of trees 1s from Standley (1937-8), Allen (1956), and Cobley (1956).

TABLE 4.--Vegetation in the three major habitats on the strand. The method of obtaining quantitative data is explained in the text. The figures in parentheses following the tree-species indicate per cent basal area.

\section{Species \\ Per Cent Per Cent Per Cent Abundance Frequency Cover}

Beach

Cenchrus echinatus Chamaecrista aspera
3

1
60

40
2

2 
TABLE 4--Continued Abundance Frequency Cover

Chamaesyce sp.

Chloris petraea

Coccolobis uvifera

Croton punctatus

Cyperus ligularis

Ipomoea Pes-Caprae

Lespedeza sp.

Sesuvium portulacastrum

Sporobolus virginicus

Vigna repens

unidentified species

$\begin{array}{rr}70 & 4 \\ 20 & 2 \\ 20 & 11 \\ 70 & 4 \\ 30 & 2 \\ 100 & 47 \\ 10 & 2 \\ 80 & 6 \\ 80 & 12 \\ 20 & 2 \\ 50 & 4\end{array}$

Cocoplum-seagrape hedge

Cenchrus echinatus

Chamaecrista aspera

Chrysobalanus 1caco

Coccolobis uvifera

Cyperus 11qular1s

Lespedeza sp.

Valerianoides jamaicensis

Vigna repens

Wedelia trilobata

unidentified species

6
1
3
4
3
41
2
14
16
2
4

6

1

3

4

3

41

2

14

16

2
4
2

11

4

47

2

6

2

4 
TABLE 4--Continued

Per Cent Per Cent Per Cent Abundance Frequency Cover

Carica papaya (2)

Cecropla obtusifolia

Cocos nucifera (50)

Crescent1a cujete (1)

F1cus sp. (2)

Guilielma utilis (2)

Hibiscus tiliaceus ( 1 )

Hippomane mancinella (1)

Inga sp. (2)

Ochroma sp. (1)

Persea americana (2)

P1thecoloblum sp. (1)

Posoquer1a sp. (1)

Schizolobium parahybum

Spondias mombin (1)

Zanthoxy lum sp. (1)

unidentified species (11)
(4)

(1)

The beach forms a typical salt-spray community.

Table 4 shows that rallroad vine (Ipomoea Pes-Caprae) was found in every transect, and accounted for 47 per cent of the cover. Sea-purslane (Sesuvium portulacastrum) and rush grass (Sporobolus virginicus) are the next most abundant beach plants. Scattered clumps of seagrape (Coccoloba uv1fera), hedgehog grass (Cenchrus echinatus) and sensitive plant (Chamaecrista aspera) are found chiefly on the distal end of the beach away from the sea. As was sald, logs and hyacinths are strewn over the beach and shoreline. A fungus (Polyporus cinnabarinus) is common on many logs. This orange fungus is very consplcuous agalnst the black sand. The total plant cover on the beach averaged 36 per cent. 
Just behind the beach is an edaphic community adapted to the strong salt-bearing winds. It is composed chiefly of cocoplum (Chrysobalanus 1caco) and seagrape. The radially creeping branches of cocoplum provide cover and resting places for the beach l1zards and bas1lisks. Total plant cover in this area averaged 70 per cent.

The largest vegetated zone on the strand is the coconut grove. Many of the trees in this zone have been planted by man. Young coconut palms (cocos nucifera) provide most of the cover in the understory. Gynerium and Heliconia are among the first plants to grow back after the undergrowth beneath the coconut trees has been cleared. These two genera are also early and important components of old-field succession in the surrounding forests. The total amount of understory cover averaged 80 per cent.

of the trees, the coconut palms are the most abundant, and constitute more basal area and cover than any other species. Breadfruit (Artocarpus communis), which furnishes an important item in the local diet, accounted for 11 per cent of the basal area. Pejibaye (Astrocaryum sp.), wild calabash (Cresentia cujete), and wild plum (Spondias mombin) were found only on the riverbank. The total tree-cover is 65 per cent and the height of the canopy about 35 to 45 feet. The average leaf-size of all trees other than palms here is in the mesophyll size-class of Raunkiaer (1934). Epiphytes are common on some tree trunks.

In the river adjacent to the cocal a few aquatic plants are found. The water hyacinth is by far the most numerous 
and conspicuous. Water lettuce (P1stia sp.), duckweed (Spirodela sp.), and bladderwort (Utr1cular1a sp.) are also common. Standley (1937-8) also lists Limnantherum, Nymphaea, Ponteder1a, and Sagittaria as common aquatic plants occurring in the rivers of costa Rica.

Events after clearing. The growth of plants in a cleared area was followed for a perlod of 27 months. In June, 1959, the plant-cover was calculated on a typical section of the beach, a plot 60 feet long and 30 feet wide. The plants with percentage of cover were as follows: Ipomoea (15\%), Sporobolus (15\%), Croton (3\%), Chamaecrista (1\%), Chlor1s (1\%). Coccolob1s (1\%), and Sesuvium (1\%). Debris in the form of logs and coconut husks accounted for 20 per cent more cover. The plot was cleared and in June, 1960, the plant-cover was as follows (whether the plants grew from roots or seeds 1s unknown): Ipomoea (21\%), sporobolus (12\%), Cenchrus (3\%), Chamaecrista (1\%), and croton (1\%). In september, 1961, 27 months after clear1ng, Ipomoea provided 20 per cent of the cover and sporobolus seven per cent. An unknown, coarse grass covered ten per cent of the area. Cenchrus, Chamaecr1sta, Chamaesyce, and Chlor1s provided ten per cent more cover.

The data indicate that Ipomoea is quick to regenerate, and 1 t provides most of the cover on the beach at all times. This dominance is maintained in spite of the fact that the trails and nests of sea turtles tear up many of the creeping stems of the vine. The pattern and speed of re-growth are important for the lizards because plants, particularly Ipomoea, provide shade when the animals are active on the beach. 


\section{THE LIZARDS: GENERAL FEATURES, RANGE, AND HABITAT PREFERENCES}

The Lizards
Both of the lizards studied are tropical species belonging to tropical genera. The genus Ameiva is found throughout Central America, South America, and the West Indies. The genus Basiliscus is usually a common member of the fauna of Central America and northwestern South America.

Ameiva quadrilineata is a medium-sized lizard reaching a s-v length of $78 \mathrm{~mm}$ in both sexes. A dorsal, brown stripe bordered by two yellow lines runs from the head to the base of the tail. These two lines are separated from another pair by a broad, lateral brownish-gray stripe. The venter is pale white in both sexes, but the venter and flanks of the male may take on a greenish-blue hue in the mating season. Basiliscus vittatus is larger than A. quadrilineata. The largest specimen collected in this study was $500 \mathrm{~mm}$ in total length. The adult males are brownish above with welldeveloped dorsal and caudal crests. A light yellow line runs from the eye posteriorly along the side for a variable distance. The female differs in having a series of black patches along the dorsum, and the crests are more poorly developed than in the male. The local name for this species is cherepo. 
Habitat Preferences

At Tortuguero, Ame1va guadr1lineata is found in all zones of the strand. It is most abundant on the beach, however, and in the open, sunny areas under the coconut trees. It is also common around and under houses but is never found in thick undergrowth. I am not aware of the existence of any other study concerning the ecology of this lizard.

Juvenile basilisks are most numerous on the beach, but the adults are always found in the cocal or cocoplum-seagrape hedge. Most adults are found in close proximity to the riverbank. Observations made on numerous hunting expeditions inland also indicated that these lizards have a preference for riparian habitats in the tropical wet forest. Gunther (1885-1902), Ruthven (1912), oliver (1937), Sm1th, Sm1th, and Werler (1952), Peters (1954), and Ne1ll and Allen (1959) have also recorded $\underline{B}$. vittatus as most common near water in other Central American countries. Stuart (1950), working in Guatemala, collected the lizard in a wide variety of habitats. Besides the two lizards that are the central subjects of this study, three other species were collected sporad1cally as a source of data on thermoregulation. These were Ame1va festiva, Ame1va pluvianotata, and Basiliscus plumifrons.

Ame1va festiva is a medium-sized teild with a yellowishgreen stripe extending from the head for a variable distance along the tail. The adults are slightly larger than adults of ㅅ․ quadrilineata. These lizards are very common in the tropical wet forest across the Tortuguero River. They are 
most abundant on the edges of clearings and in the early stages of secondary succession, before grasses have come in. They are also frequently seen foraging in the litter around large buttresses of trees. None was ever found on the strand, and no $\underline{A}$. quadrilineata was ever found with $\underline{A}$. festiva.

Several specimens of Ameiva pluvianotata were collected on the 1sland of Montserrat, B.W.I., in June, 1961. These are large teilds with a dark olive-gray dorsum sprinkled with numerous bluish-yellow spots. This lizard appears to be the ecological equivalent of $\underline{\mathbf{A}}$. quadrilineata. Like $\underline{\mathbf{A}}$. quadrilineata at Tortuguero, it is most abundant on the beaches and in the sunny paths and clearings. It is most commonly seen foraging for food between 0800 and 1000 hours, on sunny days. The lizards were collected on a narrow beach, 40 to 60 feet in width, composed of black sand. Sixty per cent of the plant cover was Ipomoea Pes-Caprae.

Basiliscus plumifrons is a large lizard, dark green above and light green on the venter. The adult males have high, well-developed crests. At Tortuguero, B. plumifrons is fairly abundant in trees along the riverbank. It is more arboreal than B. vittatus and also is more likely to be found in shaded habitats. 
ACTIVITY OF THE LIZARDS

\section{Diurnal Activity}

Both Ameiva and Basiliscus are diurnal, heliophilic lizards. Amelva and juventle Basiliscus are most active on the beach in the morning hours, The basilisks appear first, and then as ambient temperatures rise later in the morning Ameiva emerges from cover. Most of the movement onto the beach is from the cocoplum-seagrape hedge. About mid-morning, Ameiva replaces Basiliscus. There is a period when some individuals of both species are on the beach together. By noon on clear days, all lizards have left the beach.

There is a second, shorter period of activity in the late afternoon on clear days. Beginning around 1530 hours, some beach lizards may be seen foraging on the beach. As the sand and air temperatures fall, basilisks may emerge for a second period of activity. Thus, in the afternoon, the situation is reversed, and the basilisk population replaces the teild population. The numbers of individuals involved are, however, much smaller than in the morning. Males and females of both species show similar patterns of activity.

on some sunny afternoons there may be no lizards on the beach, while under cloudy conditions sporadic activity may be observed throughout the day. The activity cycle is most likely correlated with control of thermoregulation and with success in finding food. 
The activity cycles of telids living wholly in the cocal are not as sharply defined as those with home ranges extending onto the beach. Some teilds are seen in the cocal throughout the day under a variety of weather conditions. However, on clear days, most of them are active from 0900 to 1200 hours. Around houses they are often abundant throughout the day.

Activity periods of the aduit basilisks living in the cocal are less well-defined than in juveniles living on the beach. Observations of marked adults indicate that most are active throughout the morning, and many remain on coconut piles and branches all day. Because of their lower surfacemass ratio, and of the shaded habitat chosen, the adults reach their optimum temperature much more slowly than the juveniles. This probably accounts for their longer activity period.

The activity cycle of the lizards was observed in greater detail on an 8.5 acre section of the beach from June to september. The study here involved counting all the lizards seen on the plot at various times in the morning. Approximately 20 to 30 minutes were required to walk through the plot and record the lizards present. No distinction with respect to size, sex, or stage of thermoregulatory behavior was made. During each period of observation, the time, average amount of cloud-cover, and light-intensity were recorded. Light was measured by placing a General Electric light-meter on the surface of the sand. Data were then grouped into two categories: the number of lizards 
seen on the beach under "clear" as opposed to "cloudy" skies. Fig. 5 shows the relative numbers of beach lizards and juvenile basilisks on the beach under the two sorts of weather conditions. The sky was classified as "clear" if (1) the cloud cover was $0 / 10$ to $4 / 10 ;$ (2) the sun was visible more than 50 per cent of the time; and (3) if the light intensity remained between 6,000 and 8,000 foot-candles more than 50 per cent of the time during the period of observation. Conditions were classified as "cloudy" if (1) cloud cover was $5 / 10$ to $10 / 10 ;(2)$ the sun was visible less than 50 per cent of the time; and, (3) if the light registered between 1,500 and 5,000 foot-candles more than 50 per cent of the time during the walk through the study area.

In 62 periods of observation a total of 722 lizards were counted. The circles in the figure are plotted at the mid-point of each period of observation. As the figure shows, under "clear" skies the lizards are active early in the morning and leave the beach before 1100 hours. Under "cloudy" conditions, the ectotherms require a longer time to reach their activity threshold, and they can be seen foraging and basking until noon. Actually, some may remain on the beach throughout the day. Fig. 5 also indicates that Ameiva and Basiliscus are present on the beach in approximately equal numbers under "clear" skies between 0730 and 0830 hours and under "cloudy" skies between 0900 and 1000 hours. The activity of the teids almost comes to a stop when clouds hide the sun, even momentarily. Under the same circumstances, activity of basilisks diminishes to a lesser 


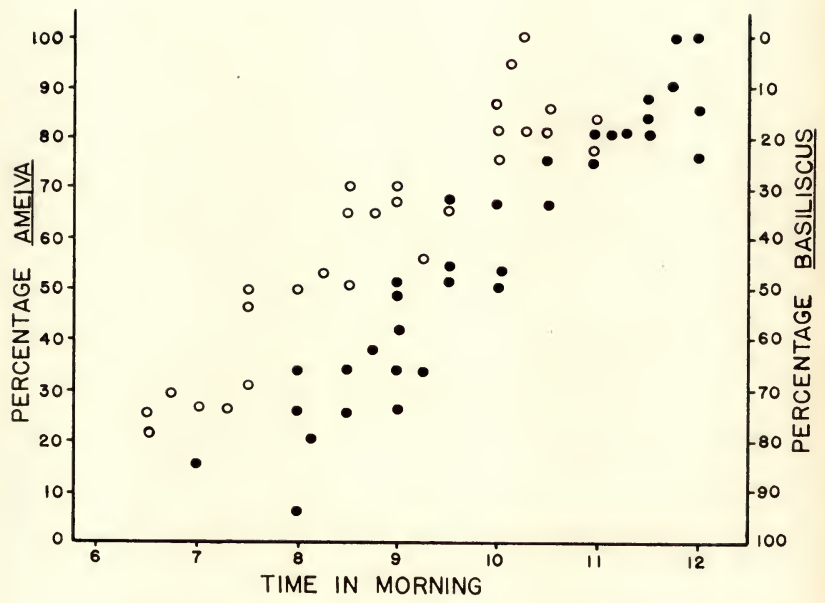

Fig. 5.--Relative numbers of Ameiva and Basiliscus seen on 8.5 acres of beach under "clear" and "cloudy" conditions. Each circle represents one period of observation of about 30 minutes. White circles represent lizards seen under "clear" skies, and black circles represent those seen under "cloudy" skies. Terms are explained in the text. 
extent. Overcast has a more pronounced effect on activity in the morning than in the afternoon. On completely overcast days, and during rain, there is no activity at all on the strand. During one such period, five days passed with no lizard being seen on the beach.

\section{Nocturnal Activity}

Ameiva was never seen after dusk in any habitat. Three juvenile basilisks were found on the beach between 2000 and 2400 hours. One of these was disturbed by a nesting sea turtle. The lizard had probably been under a coconut husk. on three other occasions juveniles were observed clinging vertically to a wire fence in the middle of the beach. They appeared to be sleeping. On september 14, four were seen on this fence; all were about three feet above the sand and within five feet of each other. No young lizards were ever seen at night on the wooden posts that supported the fence or in the coconut grove.

The sleeping habits of adult basilisks were observed in an area 300 feet long and 90 feet wide in the cocal. This plot was searched in the evening during August and September, 1960, and 1961. In 53 nights, a total of 61 (35 males, 26 females) lizards were found. On 11 nights, no lizards were seen.

Ninety-five per cent of the adults were found sleeping on the mid-rib of palm fronds, most of them in a horizontal position, with the legs folded beneath the body and the tail fully extended. Two adults were found on the leaflets of 
fronds and another was on the wire fence mentioned above. The average height of the sleeping perches was 4.6 feet (range 1-9 feet). Some lizards may climb higher, but no observations above nine feet were attempted. However, only three lizards were found at heights of above six feet during this study. Most were sleeping on low branches of young, healthy coconut trees; in 50 per cent of the observations these were on the lowest branch of the tree. Only one was found on a dead, brown branch. Two adult males were never found in the same tree. On three occastons, a male and one female, and in one instance, a male and two females, were collected from the same branch. On another occasion a pair of basilisks and a juvenile Iguana Iguana were all found on the same mid-rib, within a few inches of each other.

No correlation between the frequency of sleeping lizards and air temperature, relative humidity, phase of the moon, cloud-cover, or degree of wetness or dryness of the weather could be found. Thirty adults were found on dark, rainy nights, and 31 on dry nights. on the dry nights, 18 were found under open skies and full moon, and 13 when the sky was overcast and the moon in a quarter phase. Lizards were found sleeping under both dry and wet conditions when air temperatures ranged from $23.4^{\circ} \mathrm{C}$ to $27.2^{\circ} \mathrm{C}$, and relative humidity varied from 80 to 100 per cent. The maximum number of lizards found on any one night was five (August 9 and August 19). On both of these nights approximately 0.1 inch of rain fell. 
Numerous walks were taken through the cocal in the late afternoon, evening, and early morning in attempts to determine the approximate time the lizards mount and leave the sleeping perch. The results indicated that most of them climb up the coconut trees at dusk and leave them at dawn. The earliest time at which a sleeping perch was taken was 1630 hours. In this case the lizard selected a horizontal branch four feet above the ground and remained in the same place until 0500 hours.

One adult male was found on a palm frond at 1900 hours with a half-eaten caterpillar in its mouth, most likely caught during the last minutes of light in the grass below. It is not known why the prey was still only half-eaten one hour later.

The lizards remain on their perches even under some of the most extreme weather conditions. On one occasion two lizards were seen on the mid-rib of a palm frond with a steady stream of water flowing over them. They were still in the same position after 0.35 inches of rain had fallen in 45 minutes. The only time lizards were known to leave their perch was during a severe electrical rainstorm. on this night, three lizards were counted; and after the storm, at 2330 hours, none was in its original position.

The nocturnal activity patterns of three adult lizards were watched especially closely. One of these was a male, marked on August 9 and last seen on August 27. During this period he was recaptured seven times, between 1830 and 2000 hours, in exactly the same position. He was always four 
feet high on the mid-rib of a coconut frond. The intervals between recaptures were 1, 4, 1, 1, 2, 1, and 1 nights. The lizard was found sleeping under a variety of weather conditions. On the nights he was not in his usual position the surrounding trees were diligently examined, but he was never located in any other place.

Another adult male, observed for one month, from August 11 to September 11, was recaptured in the same position six times and on the last time was found on a branch two feet lower. The intervals between recaptures were $3,1,1,1,5$, 4, and 10 nights. The lizard was always on the perch sometime between 1800 and 1930 hours.

The third lizard, a female, was recaptured three times during an eleven-day period in August. The intervals between recaptures were 1,1 , and 5 nights. All recaptures were made on the same branch, between 1800 and 1830 hours. As in the case of the first lizard, the nocturnal emergences of the last two could not be correlated with any weather factor.

None of the three lizards was observed for more than a month. It is not known whether they changed their sleeping perches or were killed.

Other workers have seen basilisks at night. Conant (1951) found $\underline{B}$. vittatus under bridges at night in Mexico, and Neill and Allen (1959) collected B. vittatus at night on twigs in British Honduras. 


\section{THERMOREGULAT ION}

At the beginning of this century, the general concensus of opinion regarding temperature tolerances of reptiles was expressed by Gadow (1909) in this way: "Cold-blooded creatures have no specific temperature; they more or less assume that of their surroundings." Later on, reports of reptiles enduring very high temperatures began to accumulate. Some of the reports were based on superficial observations. Lizards were seen basking in the hot sun, for instance, and it was assumed that the animals did this all day. Other reports were based on data from faulty recording apparatus. This old misconception that reptiles, being "cold-blooded, " are at the mercy of the environment, and the belief that desert species, in particular, are highly thermophilic, was first questioned by Cowles and Bogert (1944), who found that reptiles are capable of exerting control over their body temperature by behavioral means, and, that the optimum temperatures of many desert reptiles are below those of some mammals and birds. Largely because of these investigations, the terms "ectotherm" and "heterotherm" (in place of "coldblooded" and "poikilotherm") came into common use.

Later, Bogert (1949a, 1949b, 1959) developed the corollary generalizations that closely related species have similar thermal thresholds even though they may live in different 
habitats and, conversely, that unrelated species are able to maintain different thermal levels in the same habitat.

The results of my work agree with contemporary ideas on thermoregulation, in that both Ameiva and Basiliscus reach their optimal thermal levels by behavioral means. It was also found, however, that these thermal thresholds may vary somewhat between congeners, depending upon the habitat. As already mentioned, selection of habitat, behavior, and thermal sensitivity are closely interrelated.

At Tortuguero, Ameiva and Basiliscus regulate their body temperatures by controlling amounts of heat gained from both solar radiation and from the substrate.

The teilds are very active animals. They constantly move about the thermal mosaic on the sand surface. They often run across very hot sand and then cool themselves in the shade of some beach plant. As a result of this behavior, they probably obtain most of their heat by conduction from the substrate. Some were seen wriggling into the sand and then lying there for a few seconds, apparently to expose more body surface for heat absorption from the hot sand. Basilisks never exhibited this behavior. Some teilds were seen basking on logs and other wood surfaces, but the majority never left the ground.

Basilisks rely more heavily on solar radiation to raise their body temperatures, although conduction is also an important source of heat. They spend most of their time sitting on perches. Adults are found most frequently perched on coconut piles and fence posts, while juveniles prefer logs. 
Sexually mature individuals spend more time on perches than juveniles. Adults appeared to orient their bodies to expose the maximum amount of surface area to the sun. This was not so apparent among the juveniles, and was rarely observed in Ameiva.

The lizards' normal period of activity on the beach supports these observations. The juvenile basilisks perch on logs early in the morning, while the teilds move to the beach later, when the sand surface has warmed up.

\section{Temperature Preferences}

Lizards were collected for temperature-information either by shooting them with .22 dust shot fired from a smoothbore pistol, or by catching them alive after careful stalking. All lizards were collected between 0600 and 1200 hours. Temperatures were taken with a schultheis quickrecording thermometer. Live lizards were handled with several layers of cheesecloth to prevent absorption of heat from the hand. Air and substrate temperatures were also recorded. Air temperatures were taken five centimeters above the site of the capture of the lizard, and the substrate temperatures were obtained by inserting one-half of the bulb into the sand or holding the bulb against a log or coconut husk, or whatever constituted the substrate.

The activity of the lizard, whether it was just emerging from cover, basking, foraging, feeding, mating, or cooling itself in the shade, was also recorded at time of capture. The lizard was usually watched for several seconds before shooting, and if it became aware of my presence the record 
was not used. Some lizards were discovered under logs, coconut piles, and other forms of cover. The following criteria were used to determine whether basilisks were active or merely basking. Activity was assumed if the head and neck were raised; if either the head or eyes were moving about as if in scanning; if it was stalking prey or running or climbing; or if it was bobbing. A lizard was considered to be basking if simply resting on a perch and not engaged in any of the above activities.

The body temperatures $\left(\mathrm{T}_{\mathrm{B}}\right)$ of 698 beach lizards, 476 juvenile basilisks, and 242 adult basilisks, along with corresponding air $\left(\mathrm{T}_{\mathrm{A}}\right)$ and substrate $\left(\mathrm{T}_{\mathrm{S}}\right)$ temperatures, are given in Figs. 6, 7, and 8 . The records have been grouped into the nearest $0.5^{\circ} \mathrm{C}$. The juvenile and adult basilisks are kept separate because of their different habitat preferences.

Several investigators (Cole 1943, Cowles and Bogert 1944, Bogert 1959) have shown that lizards obtain heat chiefly by conduction from the substrate and by direct absorption of radiant energy. Ambient air temperature is of lesser importance. Figs. 6, 7, and 8 support the conclusions of these workers and show that at time of capture the $\mathrm{T}_{\mathrm{B}}$ of most lizards were well above the $\mathrm{T}_{A}$ and $\mathrm{T}_{\mathrm{S}^{*}}$. Air temperatures above $34^{\circ} \mathrm{C}\left(93.2^{\circ} \mathrm{F}\right)$ were recorded only six times. Individual records indicate that 86.4 per cent of the beach lizards had a $\mathrm{T}_{\mathrm{B}}$ higher than $\mathrm{T}_{\mathrm{A}}$ and equal to or higher than the $T_{S}$. Similarly, the $T_{B}$ of 77.7 per cent of all juvenile 


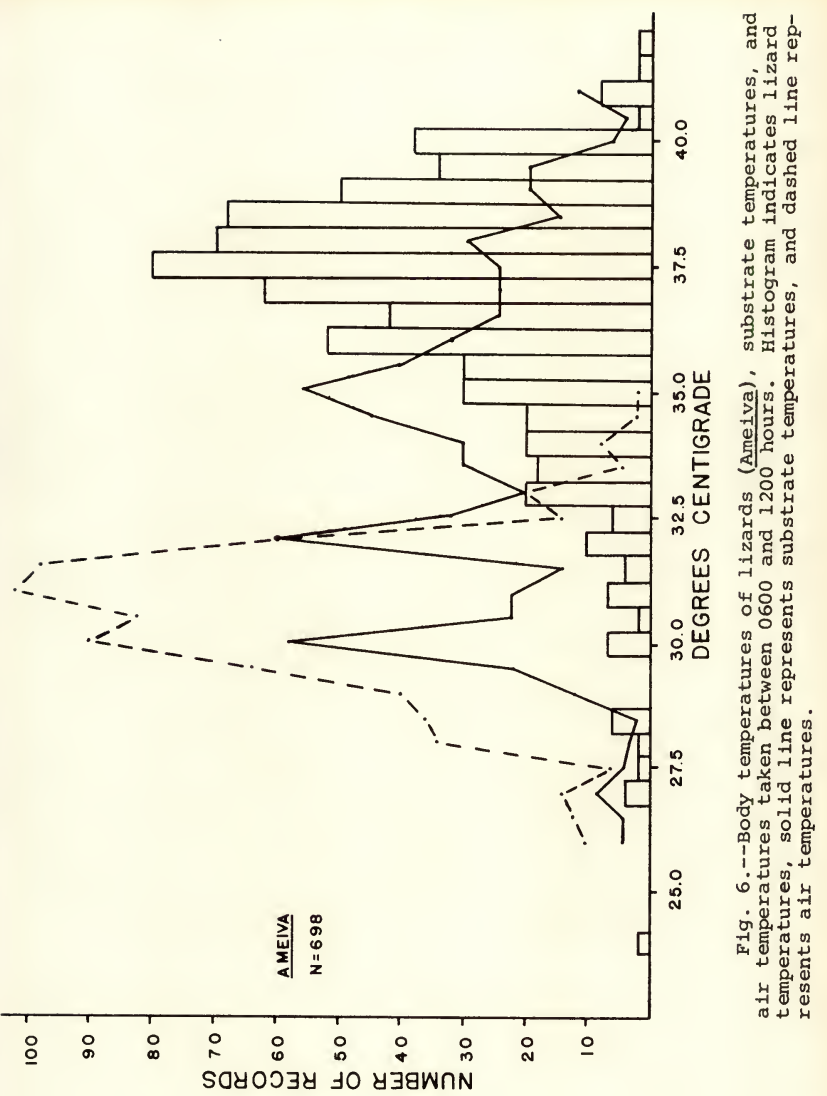




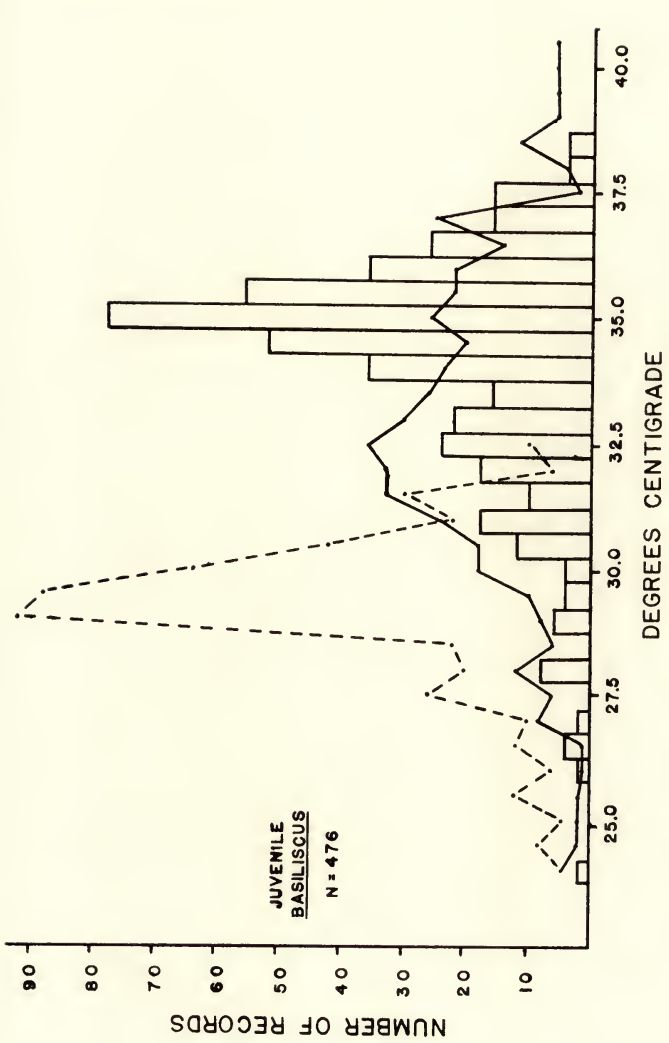

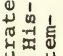

$++$

है

(1)

- $0+4$

ज.

ㄴㅇㅇㅇㅛ

ט

ता un

-1)

ता तิ की

व 0 ⿰纟

1) 엉 1

- 6 बै

त् 0 나

(1) 0 \%

(1) E 4

उ न

긴

ه

जी

개

4 대엄

तु 0 i

N.

त्

440

岑

10 40

(1) +40

$4 \pi 00$

7 兵

거 널 암

(1)

4 है

م्य

है

+ . $N$ N

ro -1 도

रो

\%

๓

I +0

I)

- U 0 त

त)

-

कित्न

का

(4) 53

(

다단

(1) $++\omega_{1}$ 


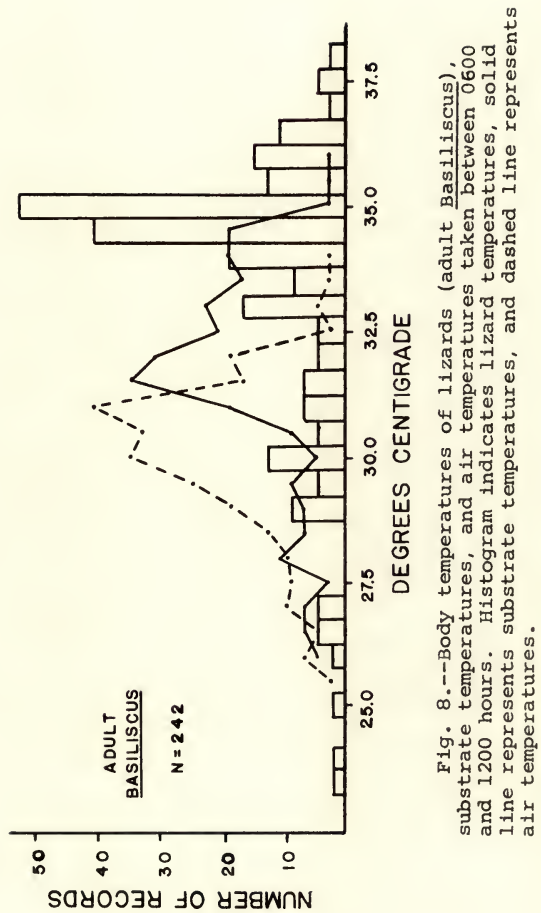


basilisks and 92.2 per cent of all adult basilisks were higher than the $T_{A}$ and equal to or higher than the $T_{S}$.

The extreme temperatures recorded by me for Ameiva were $23.8^{\circ} \mathrm{C}$ and $42.2^{\circ} \mathrm{C}$. Both individuals were adult males. The lowest and highest temperatures recorded for juvenile basilisks were $24.2^{\circ} \mathrm{C}$ and $38.8^{\circ} \mathrm{C}$. Both were females. The range of temperatures of adult basilisks was represented by a male with a $\mathrm{T}_{\mathrm{B}}$ of $23.2^{\circ} \mathrm{C}$ and another male with a $\mathrm{T}_{\mathrm{B}}$ of $38.2^{\circ} \mathrm{C}$. Since the activity of every individual was noted at time of capture, these are divided in Table 5 into the various thermal categories, as defined by cowles and Bogert (1944). The numbers of individuals in each category are obtainable by referring to Figs. 6,7 , and 8 .

The normal activity range is the thermal level at which most life-sustaining activity takes place. The ecological optimum (EO) is the mean of the normal activity range. The EO given in Table 5 were computed from temperature records of 556 beach lizards, 322 juvenile basilisks, and 170 adult basilisks. The differences between the EO of Ameiva and juvenile Basiliscus and between Ameiva and adult Basiliscus are statistically significant at the 1 per cent level $(t=$ 32.02 and 32.68 , respectively). The difference between the EO of juvenile and adult basilisks is also statistically significant at the 1 per cent level $(t=6.8)$.

The lizards included in the voluntary maximum range were those with high temperatures found lying quietly in the shade or under shelter. It is interesting to note the sudden decrease in captures of Ameiva at this level (Fig. 6). 


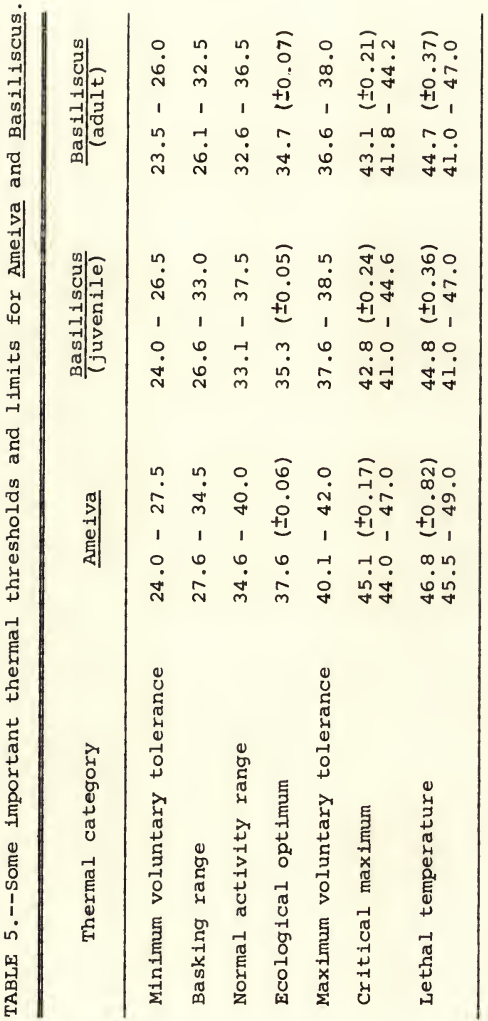


This may be an indication of their acuity of temperature discrimination. In both species there is a much shorter range between the ecological optimum and the voluntary maximum than between the former and the voluntary minimum.

For comparative purposes the temperature preferences of Ameiva festiva, Ameiva pluvianotata, and Basiliscus plumifrons are included here (see section: Habitat Preferences, for a description of collecting localities). The ecological optimum of $70 \mathrm{~A}$. festiva with s-v lengths ranging from 40 to $110 \mathrm{~mm}$ was $36.2^{\circ} \mathrm{C}\left( \pm_{0} .26\right)$. The EO of 21 A. pluvianotata with s-v lengths of 37 to $120 \mathrm{~mm}$ was $37.8^{\circ} \mathrm{C}( \pm 0.34)$. The EO of $\underline{A}$. quadrilineata and $\underline{A}$. festiva are statistically different $(t=5.38, P=<.001)$. The difference between the $E 0$ of A. quadrilineata and $\underline{A}$. pluvianotata is not significant $(t=0.59, P=>.50)$.

The EO of 20 Basiliscus plumifrons with s-v lengths ranging from 65 to $250 \mathrm{~mm}$ was $31.7^{\circ} \mathrm{C}( \pm 0.50)$. The results indicate that the EO of $\underline{B}$. plumifrons is statistically different from that of adult B. vittatus $(t=6.15, P=<.001)$.

Behavior at High Temperatures

A total of 35 beach lizards, 20 juvenile basilisks, and 20 adult basilisks were used to obtain information on the critical maximum and lethal temperatures (Table 5). The critical maximum temperature is that at which locomotive activity becomes disorganized and the lizard loses its ability to escape from conditions that will promptly lead to its death. In this paper the lethal temperature is the 
temperature at which respiration, i.e., movement of abdominal muscles, ceased and would not later be resumed. From an ecological viewpoint, the critical maximum temperature is the more important.

All individuals tested were captured one to two hours before the test. The teilds ranged in size from $38 \mathrm{~mm}$ to $65 \mathrm{~mm}$. Juvenile basilisks had s-v lengths from $38 \mathrm{~mm}$ to $62 \mathrm{~mm}$, and the adults ranged from $90 \mathrm{~mm}$ to $125 \mathrm{~mm}$. The lizards were subjected to natural temperature fluctuations by being tethered on the beach. Each time a change in behavior was noted, cloacal temperatures were taken. Sand and air temperatures were taken each minute. The following generalized composite account describes the behavior of these ectotherms at high temperatures. No differences were observed between sexes, except that the males more vigorously tried to escape.

When the body temperature of an Ameiva reaches $42.0^{\circ} \mathrm{C}$, the lizard shows considerable discomfort and vigorously tries to escape. It arches its body in attempts to minimize contact with the surface of the sand, and alternately raises the front and hind toes off the hot sand. As the temperature reaches the critical maximum the lizard has difficulty in keeping its abdomen above the ground. Respiration, as indicated by movements of the abdominal muscles, is extremely fast. In nine animals the mouth was open, and in 30 animals the tongue flicked in and out at this stage. The tail and hind legs are the first parts to show signs of heat rigor, 
then the head collapses on the ground and tremors pass throughout the body.

The temperature rises quickly between the critical maximum and the lethal point, because the lizard has lost all control of its cooling responses.

With substrate and air temperatures $50^{\circ} \mathrm{C}$ and $34^{\circ} \mathrm{C}$, respectively, four teiids with s-v lengths from $62 \mathrm{~mm}$ to $65 \mathrm{~mm}$ reached the critical maximum in an average of 5.9 minutes. With sand temperatures fluctuating between $46^{\circ} \mathrm{C}$ and $48^{\circ} \mathrm{C}$, four teilds with $\mathrm{s}-\mathrm{v}$ lengths from $38 \mathrm{~mm}$ to $50 \mathrm{~mm}$ showed signs of heat rigor in an average of 2.9 minutes.

On some occasions clouds drifted over and lowered the sand temperature. On one such afternoon an adult female was on the beach for 2.1 hours while its body temperature fluctuated between $36.0^{\circ} \mathrm{C}$ and $42.0^{\circ} \mathrm{C}$ and the substrate temperature between $36.0^{\circ} \mathrm{C}$ and $45.0^{\circ} \mathrm{C}$. At the end of this time the lizard was put into a cage, where it died three hours later. On another occasion an adult female, the temperature of which was brought down from $44.6^{\circ} \mathrm{C}$, lived for one month with no apparent ill effects.

When both young and adult basilisks are subjected to temperatures above their normal voluntary maximum they at first try to run away on their hind legs. They are, however, by no means as violent or aggressive as Ameiva in their attempts to escape. Eventually they rest in one place and open the mouth wide in attempts to cool themselves by panting. At levels just above the voluntary maximum the head and front half of the body are kept well above the ground. 
Respiration is fairly rapid. In my tests only 30 per cent of the individuals flexed their toes above the surface. At a point just below the critical maximum the lizards collapse and violent twitching occurs throughout the body. As in Ameiva, heat rigor begins in the tail and hind legs. The lethal temperature is only a few degrees above the critical maximum.

The differences between the critical maximum in Ameiva and in small and large basilisks is statistically significant at the one per cent level $(t=7.90$ and 7.35$)$.

one juvenile female basilisk died in 50 seconds when placed on sand at a temperature of $51^{\circ} \mathrm{C}$. This was most likely due to thermal shock since the lizard did not exhibit any of the characteristic cooling responses. Six lizards with s-v lengths ranging from $38 \mathrm{~mm}$ to $44 \mathrm{~mm}$ were at the critical maximum and lethal temperatures in an average of 2.4 and 3.1 minutes respectively when placed on sand registering a temperature of $48.0^{\circ} \mathrm{C}-50.2^{\circ} \mathrm{C}$. With sand and air temperatures $50.0^{\circ} \mathrm{C}$ and $33.8^{\circ} \mathrm{C}$, respectively, five adults with $\mathrm{s}-\mathrm{v}$ lengths ranging from $90.0 \mathrm{~mm}$ to $105.2 \mathrm{~mm}$ reached the critical maximum in an average of 14.1 minutes.

The temperatures of three basilisks with $s-v$ lengths from $40 \mathrm{~mm}$ to $42 \mathrm{~mm}$ were brought down from $40^{\circ} \mathrm{C}$ after being held for 15 minutes at that temperature. One of the lizards died two hours later and the other two died sometime during the night. An adult male Basiliscus with a $s-v$ length of $125 \mathrm{~mm}$ was on the beach for a period of 50 minutes. During this interval the lizard's temperature fluctuated between 
$33.4^{\circ} \mathrm{C}$ and $40.6^{\circ} \mathrm{C}$ and the temperature of the sand varied from $38.2^{\circ} \mathrm{C}$ to $40.4^{\circ} \mathrm{C}$. The air remained at $32.4^{\circ} \mathrm{C}$. At the end of 50 minutes the lizard was released and kept overnight. It died the following day at 0700 hours.

These results support the findings of others in showing that long periods of time spent at high temperatures may produce irreversible and fatal bodily damage even though the temperatures are below the critical maximum. Thus, there is not only an optimal temperature range, but also an optimal duration of exposure. Stebbins and Eakin (1958), investigating the possibility that the parietal eye is a thermoregulator, found that in four species of iguanids the parietal eye is involved in the regulation of exposure to sunlight and the amount of time spent on the surface of the ground. wilhoft (1958) found that sceloporus occidentalis cannot remain exposed to its optimal temperature for prolonged periods without harmful physiological effects.

Though inexact, the results of these simple experiments indicate that Ameiva and Basiliscus behave differently in their responses to high temperature. After the voluntary maximum is passed, Ameiva tries to protect itself by elevating the body and alternately flexing the front and hind toes. The basilisks, after a few weak attempts to escape, usually Just rest on one spot and cool themselves chiefly by panting.

\section{Nocturnal Temperature}

Ameiva was never found at night, but it was a common occurrence to find adult basilisks sleeping on the fronds of 
coconut trees (see section: Nocturnal Activity). Twentyseven lizards were removed from their sleeping perches at various hours of the night. Body and air temperatures were taken with a schultheis thermometer. These temperatures are given in Fig. 9. The figure shows that in the early evening the body temperature of the lizard is sometimes $2.0^{\circ} \mathrm{C}$ above the air temperature, while after midnight it is the same as the air temperature, or nearly so. Lizards were never found with body temperatures below the air temperature. No temperature differences between males and females were found.

\section{Reflectivity of Integuments}

Reflection from the integuments of lizards was measured with a Bausch and Lomb Spectronic 20 calorimeter with a Reflectance Attachment. The procedure followed was that of Hutchison and Larimer (1960). Pieces of integument from the mid-dorsal and mid-ventral portions of freshly killed lizards were removed, cleaned, and placed on squares of uniform gray paper. Readings were taken at intervals of $25 \mathrm{~m} \mu$ over a spectral range of $400 \mathrm{~m} \mu$ to $650 \mathrm{~m} \mu$. Each piece of skin was analyzed twice and the average taken, although the differences in the albedo did not amount to more than three per cent. The reflectance of sand collected from the surface of the beach at Tortuguero was also taken.

The reflectance curve for the black sand is confined within the range of 19 to 25 per cent throughout the wave lengths of $400 \mathrm{~m} \mu$ to $650 \mathrm{~m} \mu$. The reflectivity of the dorsal integuments of a male and female Ameiva and a juvenile 


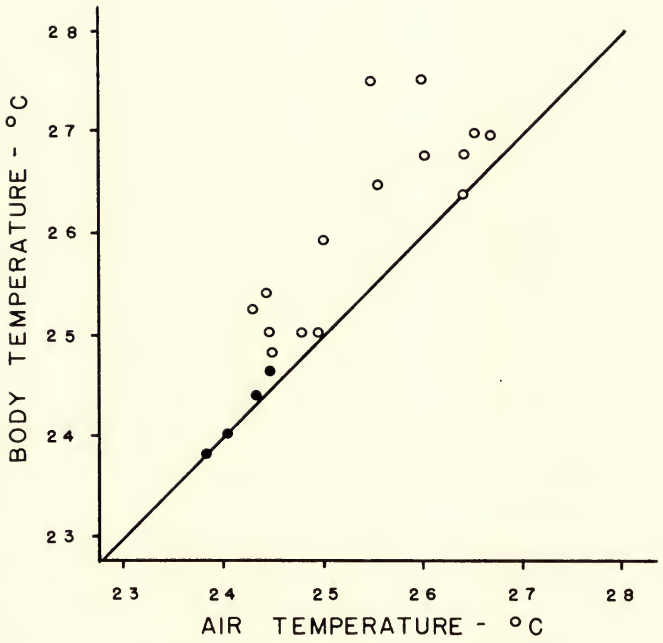

F1g. 9.--Isothermal plots of body temperatures and alr temperatures of 27 adult basilisks captured at night between 1800 and 0500 hours. Black circles indicate A.M. temperatures and represent eight 11 zards. 
basilisk varied from 18 to 25 per cent throughout the same range of wave length. It is interesting to note that although the dorsal coloration in Ameiva and in young Basiliscus is quite different, the former comprising blacks and grays, and the latter browns and yellows, both reflected approximately equal amounts of light. In Ameiva and Basiliscus the venter averaged, respectively, 9.6 per cent and 23.8 per cent higher reflectivity than the dorsum.

Reflectivity from the dorsal integument of an adult female basilisk ranged from 18 to 26 per cent. The range in an adult male was 28 to 35 per cent. Throughout the spectral range the venter in the female and male reflected 28 to 48 per cent and 24 to 43 per cent, respectively. That the adult males reflect more light than the females from the dorsum is probably due to the prominent crest extending down the back.

Kruger and Kern (1924) working with Anguis, Lacerta, and Tropidonotus estimated a lizard's skin absorbed close to 80 per cent of the incident radiation. Hutchison and Larimer (1960) found that the mean absorption of the dorsal skins of 26 individuals, representing 13 genera, over a spectral range of $400 \mathrm{~m} \mu$ to $1,100 \mathrm{~m} \mu$ was approximately 82 per cent. In this study, although a spectral range of only $400 \mathrm{m \mu}$ to $650 \mathrm{~m} \mu$ was used, the mean absorption of the dorsal integument of five lizards was 76.2 per cent.

Bundy and Neess (1958) and Hutchison and Larimer (1960) discuss the possibility that concealing coloration and thermoregulatory coloration may be synergistic. In this study 
the close relationship between the reflectivity values of beach lizards, basilisks, and beach sand, and the high light absorption leads one to suspect the two factors are indeed interrelated.

\section{Internal Pigmentation}

Because the importance of ultraviolet radiation as an environmental factor is well known, differences in internal pigmentation of the two lizards were studied.

In all size-classes of basilisks a black peritoneal lining completely envelops the posterior three-fifths of the body, from approximately the level of the liver to the large intestine. The lining thus covers the gonads in both sexes. There is a very sharp demarcation of the lining anteriorly, but posteriorly the delimitation is less abrupt. In some immature individuals the black lining is easily seen through the ventral integument. In Ameiva the black peritoneal Iining is lacking.

In discussing the function of the black peritoneal lining, Klauber (1939) states, "it could hardly be important from the standpoint of conserving heat, because of the low metabolic temperature-differential of poikilothermous animals, and the all-important part that conduction would play with respect to such heat." Both Klauber (ibid.) and Norris (1953) suggest that the black peritoneum is a protection against deleterious rays that may penetrate the skin. Hunsaker and Johnson (1959), however, concluded that internal pigmentation does not function as a protection against 
ultraviolet radiation of the shorter wave lengths. Since

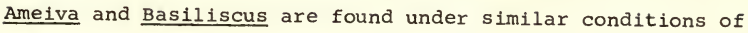
insolation but exhibit differences in temperature tolerances and thermoregulatory behavior, it seems possible that the black peritoneal lining of the basilisk serves as an internal thermoregulatory device. 
FOOD

The stomach contents of 244 beach lizards, 110 juvenile basilisks, and 210 adult basilisks were examined (Table 6). All lizards were collected in the rainy season (July and August), in 1959 and 1960. Nomenclature of arachnid and insect food follows Comstock (1948) and Brues, Melander and Carpenter (1954). The data are shown both as percentages of total food items and as percentages of stomachs in which the food items were found. Since each stomach usually contained different types of food, the latter percentages total far over 100 per cent.

A total of 2,584 food 1tems from stomachs of teilds were examined. From young basilisks there were 710 items and from adult basilisks there were 1,812 items. No differences in food were found between the sexes or years of collection. Miscellaneous material, such as pieces of barnacle shell and sand grains, was present in only two per cent of all digestive tracts examined.

Amphipods, Talorchestia fritzi and $\underline{T}$. marcuzzi formed the most common prey taken by beach lizards in the rainy seasons. These were found in 49.1 per cent of the stomachs and accounted for 27.9 per cent of the total food 1tems. These crustaceans are most abundant under stranded water hyacinths, large rafts of which float down the Tortuguero 
TABLE 6.--Stomach contents of Ameiva and Basiliscus in the rainy season.

\begin{tabular}{|c|c|c|}
\hline \multirow{2}{*}{ Food } & \multicolumn{2}{|c|}{ Ameiva } \\
\hline & $\begin{array}{l}\text { Per cent } \\
\text { items }\end{array}$ & $\begin{array}{l}\text { Per cent } \\
\text { stomachs }\end{array}$ \\
\hline \multicolumn{3}{|l|}{ Insecta } \\
\hline \multicolumn{3}{|l|}{ Odonata } \\
\hline Anisoptera & 0.0 & 0.0 \\
\hline \multicolumn{3}{|l|}{ Blattaria } \\
\hline Blattidae & 0.5 & 7.1 \\
\hline \multicolumn{3}{|l|}{ Orthoptera } \\
\hline Acrididae & 6.1 & 29.5 \\
\hline Gryllidae & 0.0 & 0.0 \\
\hline Tettigonildae & 2.4 & 7.1 \\
\hline \multicolumn{3}{|l|}{ Isoptera } \\
\hline Termitidae & 0.0 & 0.0 \\
\hline \multicolumn{3}{|l|}{ Hemiptera } \\
\hline Fulgoridae & 0.0 & 0.0 \\
\hline Lygaeidae & 0.1 & 0.9 \\
\hline Pentatomidae & 0.5 & 1.8 \\
\hline undetermined & 1.0 & 3.6 \\
\hline \multicolumn{3}{|l|}{ Lepidoptera } \\
\hline Heteroneura & 0.0 & 0.0 \\
\hline Lepidoptera larvae & 1.7 & 15.2 \\
\hline \multicolumn{3}{|l|}{ Diptera } \\
\hline Anthomyidae & 0.0 & 0.0 \\
\hline Asilidae & 1.6 & 0.9 \\
\hline Culicidae & 0.8 & 2.7 \\
\hline Muscidae & 0.1 & 0.9 \\
\hline Oestridae & 0.0 & 0.0 \\
\hline Tabanidae & 0.0 & 0.0 \\
\hline undetermined & 0.5 & 6.3 \\
\hline \multicolumn{3}{|l|}{ Coleoptera } \\
\hline Bostrichidae & 0.0 & 0.0 \\
\hline Bruchidae & 1.3 & 3.6 \\
\hline Buprestidae & 1.2 & 4.5 \\
\hline Carabidae & 0.2 & 1.8 \\
\hline Chrysomelidae & 2.0 & 7.1 \\
\hline Cicindelidae & 0.0 & 0.0 \\
\hline Elateridae & 0.2 & 1.8 \\
\hline Lampyridae & 0.4 & 3.6 \\
\hline
\end{tabular}


TABLE 6--Extension

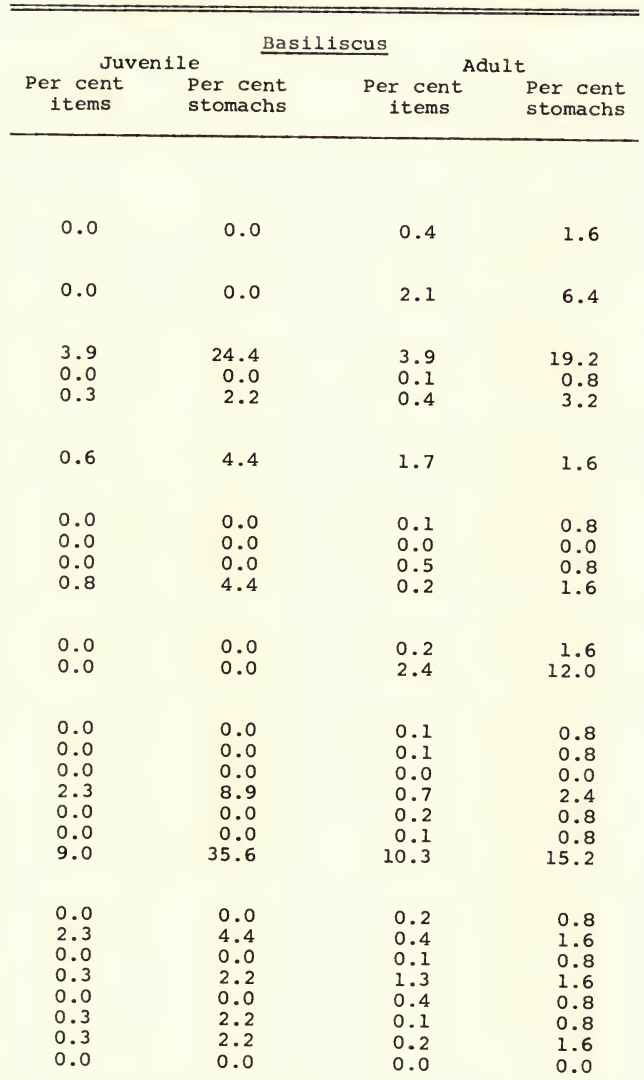


TABLE 6--Continued

\begin{tabular}{|c|c|c|}
\hline \multirow{2}{*}{ Food } & \multicolumn{2}{|c|}{ Ameiva } \\
\hline & $\begin{array}{l}\text { Per cent } \\
\text { items }\end{array}$ & $\begin{array}{l}\text { Per cent } \\
\text { stomachs }\end{array}$ \\
\hline $\begin{array}{l}\text { Scarabaeidae } \\
\text { Tenebrionidae } \\
\text { Trogidae } \\
\text { Coleoptera larvae } \\
\text { undetermined }\end{array}$ & $\begin{array}{r}1.2 \\
23.5 \\
0.0 \\
3.6 \\
6.0\end{array}$ & $\begin{array}{r}6.3 \\
46.4 \\
0.0 \\
17.0 \\
16.1\end{array}$ \\
\hline $\begin{array}{l}\text { Hymenoptera } \\
\text { Formicidae } \\
\text { Mutillidae } \\
\text { Specidae } \\
\text { Vespidae } \\
\text { undetermined }\end{array}$ & $\begin{array}{l}0.2 \\
0.0 \\
0.0 \\
0.0 \\
0.2\end{array}$ & $\begin{array}{l}1.8 \\
0.0 \\
0.0 \\
0.0 \\
2.7\end{array}$ \\
\hline \multicolumn{3}{|l|}{ Arachnida } \\
\hline Acarina & 0.9 & 4.5 \\
\hline $\begin{array}{l}\text { Araneida } \\
\text { Attidae } \\
\text { Lycosidae } \\
\text { undetermined }\end{array}$ & $\begin{array}{r}1.3 \\
12.1 \\
0.7\end{array}$ & $\begin{array}{r}8.0 \\
44.6 \\
3.6\end{array}$ \\
\hline Phalangida & 0.7 & 3.6 \\
\hline \multicolumn{2}{|l|}{ Crustacea } & 1.8 \\
\hline $\begin{array}{l}\text { Amphipoda } \\
\text { Talitridae }\end{array}$ & 27.9 & 49.1 \\
\hline Decapoda & 0.5 & 3.6 \\
\hline Isopoda & 0.0 & 0.0 \\
\hline \multicolumn{3}{|l|}{ Mollusca } \\
\hline Gastropoda & 0.0 & 0.0 \\
\hline
\end{tabular}


TABLE 6--Extension

\begin{tabular}{|c|c|c|c|}
\hline \multicolumn{4}{|c|}{ Basiliscus } \\
\hline Juv & & & \\
\hline $\begin{array}{l}\text { Per cent } \\
\text { items }\end{array}$ & $\begin{array}{l}\text { Per cent } \\
\text { stomachs }\end{array}$ & $\begin{array}{c}\text { Per cent } \\
\text { items }\end{array}$ & $\begin{array}{l}\text { Per cent } \\
\text { stomachs }\end{array}$ \\
\hline $\begin{array}{r}0.3 \\
14.4 \\
0.3 \\
2.3 \\
3.9\end{array}$ & $\begin{array}{r}2.2 \\
37.8 \\
2.2 \\
11.1 \\
17.8\end{array}$ & $\begin{array}{l}4.5 \\
9.6 \\
0.2 \\
2.3 \\
6.7\end{array}$ & $\begin{array}{r}8.0 \\
12.8 \\
0.8 \\
2.4 \\
8.0\end{array}$ \\
\hline $\begin{array}{l}2.0 \\
0.0 \\
0.6 \\
0.0 \\
2.0\end{array}$ & $\begin{array}{r}8.9 \\
0.0 \\
2.2 \\
0.0 \\
15.5\end{array}$ & $\begin{array}{r}33.3 \\
2.1 \\
1.5 \\
2.1 \\
6.2\end{array}$ & $\begin{array}{r}40.0 \\
4.8 \\
4.0 \\
8.0 \\
17.6\end{array}$ \\
\hline 0.0 & 0.0 & 0.0 & 0.0 \\
\hline $\begin{array}{l}0.8 \\
7.6 \\
0.3\end{array}$ & $\begin{array}{r}6.7 \\
26.6 \\
2.2\end{array}$ & $\begin{array}{l}0.0 \\
1.9 \\
0.1\end{array}$ & $\begin{array}{l}0.0 \\
6.4 \\
0.8\end{array}$ \\
\hline 0.8 & 2.2 & 0.0 & 0.0 \\
\hline 0.3 & 2.2 & 0.0 & 0.0 \\
\hline 44.0 & 66.6 & 0.0 & 0.0 \\
\hline 0.0 & 0.0 & 0.1 & 0.8 \\
\hline 0.3 & 2.2 & 2.8 & 1.6 \\
\hline 0.0 & 0.0 & 0.2 & 0.8 \\
\hline 0.0 & 0.0 & 0.2 & 0.8 \\
\hline
\end{tabular}


River and pile up on the beach in the wet seasons. Several investigators (Mertens 1934, Tevis 1944, Neill 1958, Mount 1961) have found Crustacea in the diets of other 1izards. Darkling beetles (Tenebrionidae) and wolf spiders (Lycosidae) were the second and third most common items found in the digestive tracts. The beetles are abundant in and under the decaying logs on the beach. In four males and six females the stomachs were entirely filled with these beetles. Wolf spiders were found in 44.6 per cent of the stomachs but accounted for only 12.1 per cent of the total food eaten.

Short-horned grasshoppers (Acrididae) were found in 29.5 per cent of the stomachs. The largest insect found in a stomach was an acridid with a total length of $32 \mathrm{~mm}$.

The stomach contents of 35 beach 1izards collected in the dry season (March and April) of 1961 were also examined. The most notable difference was the complete lack of amphipods in the diet at this time. In the dry season there is little tidal wrack and consequently little foraging on the seashore (see section: Movements). The most important food items, in order of decreasing frequency of occurrence, with percentages of total food items in parentheses, were as follows: Acrididae (29.0), Lycosidae (17.8), Tenebrionidae (15.8), Lepidoptera larvae (5.1), Chrysomelidae (5.0), Phalangida (4.5), Buprestidae (3.9), Carabidae (1.5), and Blattidae $(1.0)$.

Amphipods, darkling beetles, and lycosid spiders accounted for 63.5 per cent of the total food items eaten by 
lizards in the wet season, while grasshoppers, spiders, and darkling beetles represented 62.0 per cent of the food items eaten in the dry season.

Coleopterous larvae were more common in digestive tracts in the rainy season, while lepidopterous larvae were more common in diets in the dry season.

Hallinan (1920) examined the stomach contents of one Ameiva ameiva praesignis from Panama and found one small splder, one small acridid, 30 larvae of Coleoptera and Lepidoptera, and three pupae of Lepidoptera. Beebe (1945) recorded the food of 25 Ameiva ameiva ameiva from Kartabo, British Guiana. The most important items in order of frequency were roaches, beetles, grasshoppers, centipedes, spiders, scorpions, snails, millipedes, termites, mantids, caterpillars, Diptera, Diptera larvae, crickets, and one of each of the following: butterfly, earthworm, earwig, Hemiptera, and wasp. In these observations the low number of primarily flying insects in the diet is noteworthy. The results agree with my study of the feeding behavior of $\underline{A}$. quadrilineata (see section: Feeding Behavior).

The food of juvenile basilisks is very similar to that of the beach lizards. Amphipods represented 44.0 per cent of the food items and were found in 66.6 per cent of the stomachs. Six males and two females had stomachs full of these crustacea. The three next most common food items were darkling beetles, lycosid spiders, and short-horned locusts. These three families of insects, along with the amphipods, represented 69.9 per cent of the total food items. 
The largest insect found in a stomach was a locust $32 \mathrm{~mm}$ in length, and the smallest prey were amphipods less than $2 \mathrm{~mm}$ in length.

There is a difference in the numbers of Diptera, Hymenoptera, coleopterous larvae, and lepidopterous larvae, taken by basilisks and teilds. Only 11.1 per cent of the basilisk stomachs contained coleopterous larvae, and lepidopterous larvae were never found. On the other hand, Diptera and Hymenoptera together, accounted for 15.9 per cent of the total food items taken by basilisks, and these insects constituted 3.4 per cent of the food of Ameiva. These differences can be explained by the feeding behavior of the two lizards, as will be shown in a later section.

The dry season diet of young basilisks was also sampled. The most common food 1 tems of 22 juveniles collected in March and April, in order of decreasing frequency of occurrence, with percentages of total food items in parentheses, were as follows: Lycosidae (30.0), Acrididae (25.5), Tenebrionidae (18.3), Specidae (14.1), Bruchidae (3.1), Formicidae (2.9), and Muscidae (2.8). The food habits are very much like that of Ameiva in the same season. Amphipods are lacking in the diets of both species, while the three families of insects most commonly eaten are the same.

Brattstrom and Adis (1952) state that one small specimen of $\underline{B}$. vittatus found in Mexico, had a grasshopper (Locustidae) in the stomach. Brattstrom and Howell (1954) working in Nicaragua, found one sub-adult male $\underline{B}$. vittatus 
with grasshoppers, beetles, hemipterans, and hymenopterans in the digestive tract.

The digestive tracts of 210 adult basilisks were studied. Forty-two contained some vegetable matter, chiefly grasses, seeds, stems, and berries. In 33 per cent of the stomachs containing vegetation, this material accounted for 0-25 per cent of the stomach contents; in 31 per cent it made up 25-50 per cent; in another 22 per cent 50-75 per cent; and in 14 per cent the stomach was entirely filled with vegetable matter. In contrast, only two beach lizards and juvenile basilisks had eaten any vegetation.

In the stomachs of mature basilisks, ants are the most common items. Six males and four females had stomachs filled entirely with ants. The genera of ants most often found were Atta, Camponotus, and Dasymutilla. The largest insect taken was a queen ant, Atta sp.., with a total length of $42 \mathrm{~mm}$. Other Hymenoptera accounted for 11.9 per cent of the food items. Four males and two females had eaten only wasps.

The next most frequent food items were darkling beetles and grasshoppers. More Diptera and Hymenoptera were taken by adult basilisks than by either juvenile basilisks or beach lizards:

The data indicate that as the basilisks grow and move off the beach, they eat more ants and other Hymenoptera and Diptera in place of amphipods and spiders, as would be expected. 
The diet of 20 adults collected in the dry season of March and April was not very different from that found in the wet season. The most common items in order of decreasing frequency of occurrence, with percentages of total food items in parentheses, were: Acrididae (15.1), Formicidae (25.0), Vespidae (12.5), Tenebrionidae (12.4), Mutillidae (6.5), Scarabidae (5.4), Muscidae (4.0), Lycosidae (3.5), and B'lattidae (4.0). Vegetable matter was found in four stomachs.

Hallinan (1920) examined the stomachs of three basilisks from Panama and found some Coleoptera, Odonata, Acrididae, larvae of Lepidoptera, a fish, and some fruit. Barden (1943a) recorded the stomach contents of 99 Basiliscus basiliscus collected during July and August at Barro Colorado Island, Panama. He found ants to be the most abundant single item, making up 26.14 per cent of the total food items and present in 68 stomachs. The biggest difference noted between the diet of $\underline{B}$. basiliscus and $\underline{B}$. vittatus was the rare occurrence of Tenebrionidae in the diet of the former.

Termites are virtually absent from the diets of all lizards studied. The conspicuous nests of these insects are scattered throughout the strand, and the insects are especially abundant in the rotting logs on the beach. Their inaccessibility may account for their not being eaten more. frequently. But, on two occasions at approximately 15301630 hours, both beach lizards and basilisks were observed feeding on winged adult termites which were swarming in thousands. Hardened termite nests in the cocal were favorite basking places of some adult basilisks. 
The preponderance of diurnally active insects in the digestive tracts of Ameiva and Basiliscus correlates well with the normal period of activity of the lizards.

\section{Size of Prey}

In determining the feeding role of an animal it is not only the kind of food that is significant. The size of the food units is also important, especially in non-chewing animals like Ameiva and Basiliscus. In the present study, the length of prey in all stomachs was carefully measured with dial calipers to the nearest $0.5 \mathrm{~mm}$. The items were divided into the following length classes: class $1=$ under $2.0 \mathrm{~mm}$; class $2=2.0-3.0 ;$ class $3=3.1-4.0 ;$ class $4=4.1-6.0$; class $5=6.1-9.0 ;$ class $6=9.1-15.0 ;$ and class $7=$ above $15.0 \mathrm{~mm}$. Results can be summarized as follows (figures in parentheses represent the percentages of total food items in each category for Ameiva and Basiliscus respectively): class $1(3-1)$, class $2(11-11)$, class $3(18-20)$, class 4 $(36-41)$, class $5(21-22)$, class $6(8-4)$, and class 7 (3-1). The results show that beach lizards and juvenile basilisks not only eat the same kind of food, but also take prey of the same size. The two lizards are thus direct competitors for food during the periods they are on the beach together, and are indirect competitors for food at all other times.

The size of prey taken by juvenile and adult basilisks differs greatly. Fig. 10 shows this ontogenetic change in feeding. Ninety-six per cent of the food of the adult is over $4.1 \mathrm{~mm}$ in length, compared to 68 per cent over that length in juveniles. 


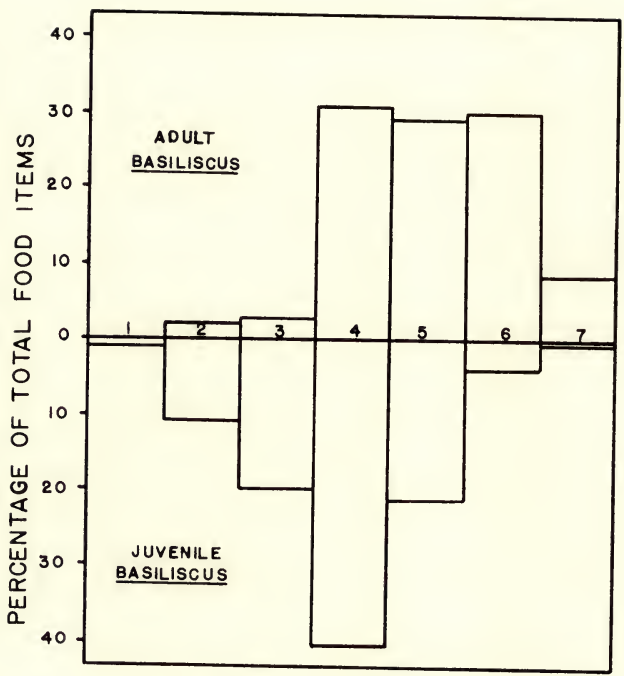

Fig. 10.--Size-frequency distribution of food items eaten by juvenile and adult Basiliscus. Figures on abscissa refer to size of food categories. See text for values. 
The change in feeding habits may be emphasized by using Hotton's (1955) functional classification of food, which takes into account weight of integument and activity of prey. Under this system, the juvenile basilisks may be characterized as feeding on animals with intermediate to high activity and light integuments. The adults, on the other hand, feed on insects with low to high activity and heavy integuments.

\section{Feeding Behavior}

Although Ameiva and Basiliscus compete for food on the beach, their methods of feeding are very different.

Ameiva moves about slowly with the tail dragging on the ground. The head is pushed along in a "grubbing" fashion and the tongue is frequently flicked out. Hardly any depression in the sand surface or crack in a log escapes the lizard's probing attention. This explains why more larvae are found in the diet of Ameiva. Every few seconds a foraging Ameiva stops and raises its head as if looking around to orient itself. Its movements often take it across caravans of leaf-cutting ants, but the ants are never eaten. The following observations taken from field notes have some bearing on the feeding behavior of these teilds.

On June 24, at 1100 hours, I observed No. 22, a female with a s-v length of $64 \mathrm{~mm}$, feeding around a log in the middle of her home range. The lizard was stealing and eating larvae which ants were carrying. She would take the larvae with a flick of the tongue. If the ant failed to let go of its burden, the lizard would take the larva in her mouth and shake her head until the ant released its hold. One time she used a front leg to separate the ant. She always succeeded in getting the larva one way or another. She also ate some brown pupae which the ants were carrying. After swallowing the food, she flicked out her tongue several times. She never ate 
the adult ants. The ants were about $15 \mathrm{~mm}$ in length and black, while the larvae were $6 \mathrm{~mm}$ and white. The lizard could see either the small white larva or the movement of the ant carrying it, or both, at a distance of at least 18 inches.

on July 31, I dropped some white bread crumbs from a window of the camp near an adult male that was actively searching for food. The lizard saw the crumbs fall, immediately ran to them and ate them. When the crumbs were hidden by vegetation, the lizard could not find them, even though he might be only a few inches away. other beach lizards ate cookie crumbs, and Larry ogren has imformed me that he has seen them eat pieces of papaya.

It is well known that carnivorous lizards and snakes usually eat only live prey, although some snakes devour recently killed victims. Although the observations reported here seem unusual reversals of the feeding habits of carnivorous lizards, Grant (1931) found that Ameiva exsul in Puerto Rico fed principally on refuse and vegetation including onion trimmings and potato peelings. In spite of these aberrations, however, the high percentages of certain prey in the diet support Cott's (1957) statement that " . . . 1izards are selective, rather than indiscriminate, in their feeding habits, that they associate appearance with taste."

Both immature and adult basilisks are less active in their feeding behavior. They usually sit motionless on a $\log$ or coconut husk and wait for insects to crawl or light near by. Then a sudden, well-directed lunge nearly always succeeds in capturing the victim. While waiting and scanning the area, the basilisk moves only his head and eyes. A few juveniles were seen actively foraging for food, in the manner of the teilds. 
Mature basilisks can see the movement of a grasshopper at a distance of at least 24 inches. Sometimes they will leave the perch and stalk an insect, which is eaten headfirst. If the lizard has left its perch to stalk an insect it will sometimes return to the same perch to swallow the prey, usually with vigorous head-bobbing during and after the swallowing process. Complete ingestion never took more than ten minutes.

Observations indicate that the juvenile basilisks are somewhat "opportunistic" in their feeding behavior. They seem to be present when insects are being scattered or attracted by other activities, for example, around freshly opened sea turtle nests. Dogs and people, aided by vultures and crabs, open and destroy many turtle nests during the summer season. As a result, some eggs are broken and scattered, and these attract insects. Both Ameiva and Basiliscus take advantage of this insect food. of the two, Basiliscus appears to be the more inclined to this opportunistic behavlor, being found around nests even on cloudy days. Basilisks are also seen feeding on insects attracted to Iguana nests which have been similarly opened.

Another interesting relationship involves basilisks and crabs. On August 10, 1960, I watched some ghost crabs (ocypode quadratus) dexterously open and eat hundreds of barnacles (Lepus anatifera), which were attached to a stranded log. At the same time there were three juvenile basilisks around the log feeding both on insects attracted to the opened barnacles and on the remains of the barnacles 
themselves. Although this was observed only once, the abundance of stranded logs and barnacle remains suggests that such behavior may not be abnormal. This tendency might explain the miscellaneous pieces of shells found in the stomachs of a few lizards.

When both Ameiva and juvenile Basiliscus are on the beach together it is not unusual to see several teilds grubbing beneath a log, and a basilisk or two sitting on top of the same log. On July 10, 1959, I saw a basilisk sitting on a log jump and successfully seize a beetle which was scared up by a grubbing Ameiva.

In summary, it should be mentioned that both Ameiva and Basiliscus depend chiefly on sight to obtain food. The probing that Ameiva does with its snout, however, suggests that the sense of smell is also important. This supports Oliver's (1955) statement that the long-tongued teiids rely more on the tongue-and-Jacobson's-organ-system in foraging, while the iguanids use vision primarily. 
MOVEMENTS

\section{Methods of study}

A total of 215 beach lizards, 160 juvenile basilisks, and 100 mature basilisks were individually marked by clipping toes. Seventy per cent of the teilds and 60 per cent of the basilisks were recaptured from one to 24 times. Approximately 60 per cent of the recaptures in each species were females.

The locations of all recaptures were accurately plotted on a detailed map of the study area. The peripheral locations were connected with straight lines and the area computed with a planimeter. Each polygon was traced three times and the average recorded. No more than one recapture was plotted for any individual on any one day. This was done in order to avoid any unnatural movements the lizard might have made as a result of being handled the first time.

The number of recaptures necessary to estimate the size of the home range was determined by inspection of the data. The point above which there was no further correlation between number of recaptures and size of home range was taken as the minimum number of recaptures necessary to estimate home range. For juvenile Ameiva, size of home range was based on a minimum of 13 recaptures; the corresponding number was 12 for adult female Ameiva; for adult male Ameiva it 
was 14; for juvenile basilisks, 14; and for adult basilisks, 10.

The home ranges of Ameiva and juvenile Basiliscus were derived chiefly from data on individuals inhabiting the beach and cocoplum areas. Those of adult basilisks are from lizards living in the cocal.

\section{Size of Home Range}

In this study "home range" means the area covered after a minimum number (see preceding section) of observations had been made during a four-month period from June to september.

Most of the home ranges of Ameiva and juvenile Basiliscus are irregular in shape and extend from the wave-cut bank to the cocoplum hedge. The home ranges of adult basilisks are more or less circular. Tables 7 and 8 show the computed home ranges for 37 teiids and 43 basilisks.

The following notes refer to " $t$ " tests using the mean home range in acres. The hypothesis in all cases is that the mean home ranges of the pair being tested are equal. Statistical significance is set at the 1 per cent level. There is no significant statistical difference between the mean home ranges of juvenile male and juvenile female Ameiva $(t=1.38)$; juvenile and adult female Ameiva $(t=1.04)$; juvenile male Ameiva and juvenile male Basiliscus ( $t=1.18)$; juvenile male and juvenile female Basiliscus ( $t=2.66)$; juvenile and adult female Basiliscus ( $t=0.47$; and adult male and female Basiliscus $(t=0.24)$. The differences between the mean home ranges of the following are statistically 


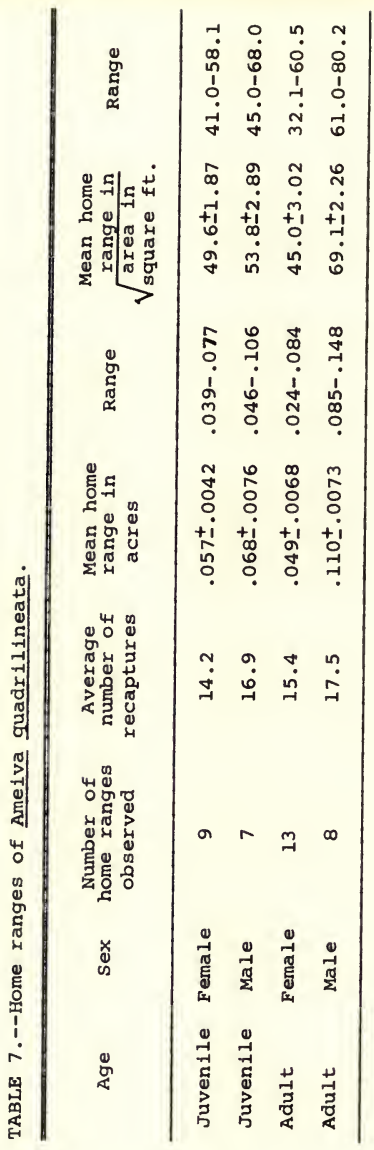




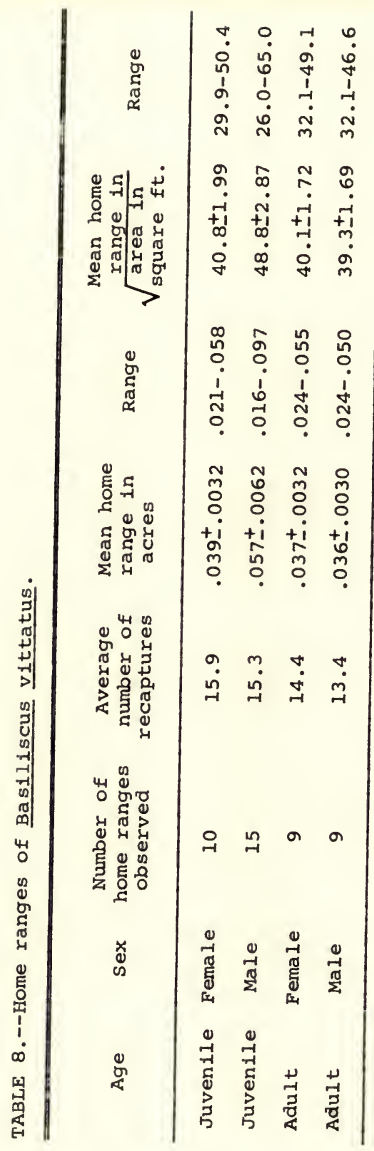


significant: juvenile and adult male Ameiva $(t=4.32)$; adult male and female Ameiva $(t=6.47)$; juvenile female Ameiva and juvenile female Basiliscus $(t=3.60)$; and juvenile and adult male Basiliscus $(t=3.13)$.

There is no significant difference in size of home range between juvenile male and female Ameiva. Both males and females have home ranges which correspond to a square about 50 to 54 feet on a side. During the course of their lives the males almost double their traveling distances, but the females become more restricted in their movements. This might be explained by the fact that adult females have a well-defined center of activity (see following section), whereas the more extensive peregrinations of the males would be advantageous during the breeding season. The average home range of adult males is about 1.62 times as large as that of the juveniles and approximately 2.24 times as large as that of adult females.

'The difference between the mean home ranges of juvenile male and female basilisks is not statistically significant at the 1 per cent level, but is significant at the 5 per cent level. Juvenile female basilisks have the smallest home range of any lizard inhabiting the beach. This is 0.039 acres which corresponds to a square only 40.8 feet on a side.

Juvenile and adult basilisks act as ecologically separate populations. They occupy home ranges that do not overlap spacially. As basilisks grow and move off the beach, 
the size of the home range of the female does not change significantly while that of the male does.

The home ranges of adult male and female basilisks are similar in size, but those of adult Ameiva are statistically different. Again this might be correlated with the habitat change of the males. Barden (1943b) marked some Basiliscus basiliscus in Panama and found that most of these lizards were seen again where first marked, or within a distance of 15 to 20 feet.

The home ranges of the lizards overlap extensively on the beach. A certain log may be the center of activity of an adult female and at the same time the favorite basking site for a number of young basilisks. The large amount of overlap in the home ranges of adult male Ameiva suggests that they do not maintain territories.

There is very little overlap in the home ranges of juvenile and adult Basiliscus. The only place where both meet are in the cocoplum-seagrape hedge between the beach and cocal and in scattered clumps of seagrape on the beach. on this study area, the home ranges of most adult basilisks centered around a pile of coconut husks. Most observations involved a single male or female on or around each mound. The data from three years' observations of combinations of males and females on the same coconut pile can be summarized as follows: 1959, a total of 25 observations, 75 per cent 1 male or 1 female, 25 per cent 1 male and 1 female; 1960, 50 observations, 50 per cent 1 male or 1 female, 40 per cent 1 male and 1 female, 9 per cent 1 male and 
2 females, 1 per cent 1 male and 3 females; 1961, 30 observations, 60 per cent 1 male or 1 female, 40 per cent 1 male and 1 female. Two adult males were never seen on the same pile at the same time.

Since fighting among mature basilisks was never observed, it cannot be said that any part of the home range is defended in the territorial sense. The home ranges of some beach lizards overlap those of basilisks in the cleared areas of the cocal. The decaying coconut mounds are ideal feeding places for the teiids. No form of aggressiveness was ever observed between the two species.

The limited number of recaptures in March and April indicates that the home ranges are smaller in the dry season. The average home range of three juvenile beach lizards during this period was .057 acres. This was based on an average of eight recaptures per animal. Four adult males and seven adult females were roaming over .090 and .040 acres respectively. These results were based on an average of nine recaptures. The home range of five juvenile basilisks, as shown by an average of eight recaptures each, was .031 acres. Adult basilisks were recaptured too infrequently to justify any conclusions.

The beach lizards were seen and captured more frequently in the cocoplum-seagrape hedge in the dry season than in the rainy season. The two most important factors accounting for the smaller home range during the dry season are (1) high sand-surface temperatures and (2) lack of tidal wrack on the seashore. When wrack, mainly made up of water 
hyacinth, is sparse, amphipods are few and lizards rarely make forays onto the shore.

\section{Center of Activity}

Numerous workers (Fitch 1940, Stebbins 1944, Blair 1960) have shown that within the home range there is a center of activity from which the lizards make occasional excursions farther away.

Juvenile beach lizards of both sexes appear to have a weekly defined center of activity. This position is usually a log or pile of logs and it may occur anywhere within the home range. In some cases it was near the seashore while in others it was in the middle of the beach. The center of activity serves chiefly as a feeding site, but may also provide a source of cover and to a lesser extent act as a basking place.

The adult females have a strongly defined center of activity. One could predict, from day to day, what females to expect around certain logs. When pursued, a female lizard almost always ran toward her favorite $\mathrm{log}$. On several occasions a lizard ran between the feet of the observer standing between her and her log.

Adult male Ameiva do not appear to have a specially favored site, but roam more or less randomly throughout the expanse of their home range.

Juvenile basilisks, likewise, appear to have no particularly strong attachment for any object or region within the home range. A few seemed somewhat attached to certain 
patches of Sesuvium and were found in these places up to six consecutive days, but most were recaptured and observed at random locations. The lizards are frequently seen basking on logs but show no preference for any particular log.

Mature basilisks, on the contrary, have a strong attachment for a certain region within their home range. This is usually a pile of coconuts, which serves as both a basking and a feeding site.

The center of activity may change over a period of months. The change may be forced upon the lizard by outside factors, or it may be a voluntary movement. For example, when local inhabitants chopped up a log for firewood, two beach lizards were forced to shift their center of activity to a neighboring pile of coconut husks. In another case, in September, an adult female Ameiva was frequently captured under a pile of planks near the seashore, but in March, she was most frequently found on a sandy path in the cocoplumseagrape hedge. A third case was that of a juvenile basilisk which showed a definite preference for a certain patch of Sesuvium on the forebeach, and was recaptured every morning for eight days in the same area. After high tides and the meanderings of a sea turtle destroyed the site, the lizard was most frequently captured in another clump of sesuvium. 50 feet away.

Two observations made in July suggest that the center of activity may at times be defended. Both observations involved Amelva. In one case an adult female (No. 1) was feeding on some insects at the base of a log, her center of 
activity. Another adult female (No. 2) approached from the opposite side of the log, grubbed around for a couple of minutes, and then ran over the log. Lizard No. 1 immediately saw No. 2 and chased after her for about 20 feet. No. 1 then returned to the same $\log$ and commenced feeding. Two juvenile basilisks sat on the log throughout the entire incident. On another occasion an immature male that I scared while he was foraging among some hyacinths on the seashore, ran up the bank and hid beneath a plank. He was immediately chased out from under the other end of the plank by an adult female. The chase continued into the cocoplum. These two observations may be exceptions, since throughout three years' study, several lizards were, on repeated occasions, seen feeding or thermoregulating in close proximity to each other. 
GROWTH AND LONGEVITY

The rates of development of 32 beach 1 izards and 55 basilisks are given in Tables 9 and 10. The tables are

TABLE 9.--Growth rates of Ameiva. All measurements are in milimeters.

\begin{tabular}{ccccc}
\hline $\begin{array}{c}\text { s-v } \\
\text { Size } \\
\text { roup }\end{array}$ & Sex & No. & Growth per 15 days \\
\hline $32-40$ & - & 8 & 6.0 & $1.0-9.3$ \\
$41-50$ & Male & 1 & 3.7 & $3.7-3.7$ \\
$41-50$ & Female & 3 & 2.8 & $2.1-3.5$ \\
$51-60$ & Male & 4 & 1.5 & $0.0-4.7$ \\
$51-60$ & Female & 3 & 1.0 & $0.0-1.7$ \\
$61-70$ & Male & 4 & 1.2 & $0.2-2.3$ \\
$61-70$ & Female & 9 & 0.6 & $0.0-1.2$ \\
\hline
\end{tabular}

patterned after Cagle's (1946) table of growth rates in Hemidactylus garnoti1. The data indicate that males of both species grow slightly faster than females. However, the range of measurements for each size group shows great individual variation in growth rate.

The largest Ameiva and Basiliscus collected were males and had s-v lengths of $79 \mathrm{~mm}$ and $138 \mathrm{~mm}$ respectively. The largest female telid had a s-v length of $78 \mathrm{~mm}$, and the biggest female Basiliscus was $125 \mathrm{~mm}$ long from snout to vent. 
TABLE 10.--Growth rates of Basiliscus. All measments are in millimeters.

\begin{tabular}{ccccc}
\hline $\begin{array}{c}\text { s-v } \\
\text { Size } \\
\text { group }\end{array}$ & Sex & No. & Growth per 15 days \\
\hline $35-40$ & - & 11 & 7.5 & $2.0-11.0$ \\
$41-50$ & - & 16 & 6.3 & $0.0-9.0$ \\
$51-60$ & Male & 4 & 5.1 & $3.0-6.0$ \\
$51-60$ & Female & 1 & 5.0 & $5.0-5.0$ \\
$61-70$ & Male & 2 & 3.9 & $3.0-4.8$ \\
$61-70$ & Female & 1 & 2.9 & $2.9-2.9$ \\
$71-80$ & Male & 1 & 2.5 & $2.5-2.5$ \\
$71-80$ & Female & 3 & 2.7 & $2.5-2.8$ \\
$101-110$ & Male & 1 & 0.2 & $0.2-0.2$ \\
$101-110$ & Female & 8 & 0.3 & $0.2-0.4$ \\
$111-125$ & Male & 7 & 0.1 & $0.0-0.2$ \\
\hline
\end{tabular}

The ecological longevity of these lizards is normally less than a year. Only 10 (4 males, 6 females) of 115 marked adult beach lizards were recaptured after a period of 12 months. None were found two years after marking. Eight (6 males, 2 females) of 100 adult basilisks were recaptured after an interval of 13 months, and two males were still on the study area two years after marking. The faster-growing of these two added $5.3 \mathrm{~mm}$ to 1 ts original $112.0 \mathrm{~mm}$. In the one case in which a juvenile basilisk, marked (on the beach), was recovered as an adult (in the cocal), the lizard's s-v length had increased from $40 \mathrm{~mm}$ to $135 \mathrm{~mm}$ over a period of 13 months. 
one pair of adult basilisks was kept in captivity. The female died, without apparent cause, eight months after confinement, while the male is still living after 20 months. During this time he has been fed a diet of cockroaches and grasshoppers and his s-v length has increased from $110 \mathrm{~mm}$ to $116 \mathrm{~mm}$.

\section{Ontogenetic Changes in Length of Tail}

Measurements of snout to vent and tail were normally taken from live lizards in the field. From records of lizards with complete tails, 100 individuals of each species and sex were picked at random. The ratios of tail/snoutvent lengths were plotted and regression lines were fitted to the scatterplots by the method of least squares. The results are shown in Fig. 11. It should be emphasized here that no hatchlings of either species were ever collected. If measurements of these were avallable, the regression lines would be different.

The equations for the regression lines of male and female Ameiva are $\mathrm{Y}=184.34+0.13 \mathrm{X}$ and $\mathrm{Y}=189.90+0.03 \mathrm{X}$, respectively. The figure indicates that there is little allometric tail growth in the males and practically none in the females with s-v lengths of $40.0 \mathrm{~mm}$ to $75.0 \mathrm{~mm}$. The tail averaged from 188 to 194 per cent of the $s-v$ length in all sizes of lizards examined. The extremes were represented by a juvenile male with a s-v length of $34 \mathrm{~mm}$ and a tail only 1.7 times as long, and an adult male with a s-v length of $78 \mathrm{~mm}$ and a tail 2.2 times as long. 


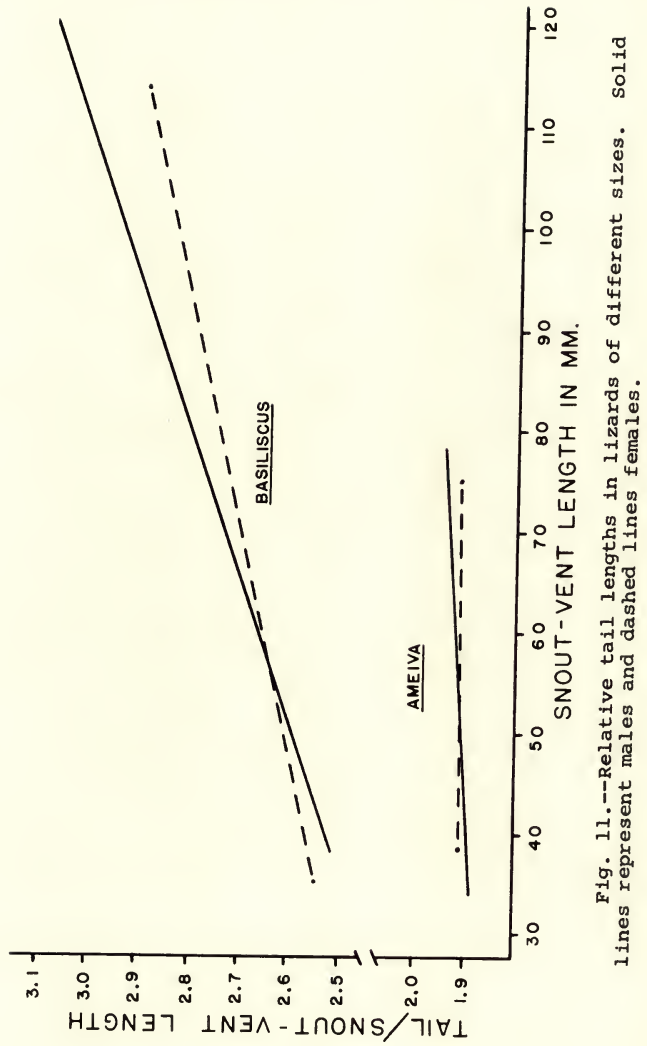


The regression lines of the male and female basilisks are represented by the equations, $Y=225.48+0.69 \mathrm{X}$ and $\mathrm{Y}=238.93+0.45 \mathrm{X}$, respectively. The results indicate ontogenetic change in relative lengths of the $s-v$ and tail. In males with a s-v length of $40.0 \mathrm{~mm}$ the tail averages 253 per cent of the s-v length, and this increases to 308 per cent at a s-v length of $120 \mathrm{~mm}$. The changes are not as great in female basilisks. The smallest Basiliscus examined was a female with a s-v length of $35 \mathrm{~mm}$ and a tail 2.3 times as long as the $s-v$. The largest examined was a male with a $s-v$ length of $120.0 \mathrm{~mm}$ and a tail 3.15 times as long. 
REPRODUCTION

Size at sexual Maturity

The criteria by which sexual maturity was determined were presence of oviducal eggs, relative enlargement of the testes, and relative convolution of the vas deferens. In cases of doubt, smears were made from sections of the vas deferens and epididymis, and the spermatozoa were examined for maturity. The information given below pertains to lizards collected from June to september, over a two-year period. Sexually mature individuals of both sexes and species were found during each of the four months.

The smallest Ameiva in which oviducal eggs were found measured $48 \mathrm{~mm}$ from snout to vent. The number of eggs varied from one to four in 18 telids with s-v lengths of $62 \mathrm{~mm}$ to $73 \mathrm{~mm}$. The mean number of eggs was 2.0, and most of the eggs were spherical.

The smallest basilisk containing oviducal eggs had a s-v length of $83 \mathrm{~mm}$. There was one egg in each oviduct. Twenty-five basilisks, with s-v lengths of $92 \mathrm{~mm}$ to $125 \mathrm{~mm}$, contained two to six eggs, the average being 4.2 . The majortty of eggs were oval. In both species there was a tendency for larger lizards to contain more eggs. This trend was most noticeable in the basilisks. 
The smallest male Ameiva and Basiliscus found in a breeding condition were, respectively, $58 \mathrm{~mm}$ and $80 \mathrm{~mm}$ in s-v length. Of 39 beach lizards with s-v lengths of $56 \mathrm{~mm}$ to $65 \mathrm{~mm}$, seven were in a breeding condition. Sixty-five per cent of 40 individuals over $66 \mathrm{~mm}$ showed indications of sexual maturity. Five of 18 basilisks with s-v lengths of $80 \mathrm{~mm}$ to $89 \mathrm{~mm}$, contained viable spermatozoa, while 84 per cent of 52 specimens over $90 \mathrm{~mm}$ were sexually mature.

Though by no means conclusive, these data indicate that the most active breeding population of beach lizards at this time of the year comprises females over $62 \mathrm{~mm}$ and males over $66 \mathrm{~mm}$ in s-v length. Similarly, the most active breeding population of basilisks is composed of females over $92 \mathrm{~mm}$ and males over $90 \mathrm{~nm}$ in $\mathrm{s}-\mathrm{v}$ length.

\section{The Breeding season}

Due to the irregularity of the collecting periods, no quantitative year-round data on the breeding cycles are available. However, juvenile beach lizards and basilisks were seen during every sojourn at the study area. They were on the beach in June, July, August, september, January, February, March and April. Local inhabitants say juveniles are on the beach throughout the year. Observations indicated that the largest populations of juvenile telids and basilisks are present in August and september.

\section{Courtship and Mating Behavior}

The complete mating behavior of Ameiva was observed under natural condition on June 22, 1959; June 11 and 12, 1960; 
and July 9, 1960. The sequence of events was similar in every instance. Three matings were observed in the morning and one in the late afternoon. All the matings took place in the cocal. No signs of courtship or mating were ever seen on the beach or in the cocoplum-seagrape hedge. During the mating season, the flanks of most males became greenishblue, but no color changes were observed in females.

The mating activity is as follows. The male rubs his cloacal region on the ground, while moving forward about three inches. This is repeated at intervals of several seconds. The tail and posterior portions of the body are held rigid at this time. The male then actively and aggressively seeks a female. He nips her at the base of the tail and then works his way quickly up and over her back, getting a $j$ aw hold at the base of her neck and securely holding her in this position. His front legs are just behind those of the female. He twists his body around, bringing the cloacal region into contact with that of his partner, and the hemipenis is inserted. Coitus involves two or three convulsive thrusts, lasting about three seconds. This is usually repeated two or three times after an interval of about five seconds. The male then releases his grip and the female slowly moves away. The male remains quietly in the same place for a few seconds while the hemipenis is retracted. The complete mating act, from the time when the male rubs his cloaca on the ground to the time the female is released, varies from three to nine minutes. Differences in time are due largely to varying receptivity of the female. In three 
matings the female was very receptive while in the one which lasted nine minutes, the female struggled vigorously throughout the operation.

In all but one instance the male and female were found feeding or basking in close proximity to each other a few minutes after copulation. Occasionally the male would run up to the female and poke at her with his snout. If other lizards of either sex moved into the immediate area, the male would chase the intruder out and then immediately run back to the female. The size of the area defended in this fashion was about 20 square feet. The only lizard tolerated in this area was the female with whom the male had just mated. Observations were in all cases discontinued after 5 to fifteen minutes when the lizards moved out of sight.

The post-mating behavior of the fourth male was very different. This individual successfully courted another female 20 minutes after his first mating, and did not exhibit aggressive or territorial behavior of any sort at any time.

Incomplete matings were observed on several occasions in June and July. In all of these attempted matings, the female wriggled furiously and escaped. The male pursued the female for a short distance but soon gave up and directed his attention to other lizards in the immediate vicinity. on one occasion, a male was seen to direct his attention to two smaller non-breeding males after being rejected by a female. In both instances, the smaller lizards seemed to sense the approach and intent of the aggressive male and simply ran away before there was any bodily contact. 
Observations suggest most mating takes place just before the summer rainy season, but the presence of young on the beach at least in eight months of the year would seem to indicate that some mating takes place throughout the year.

One pair of Ameiva pluvianotata was found mating on the island of Montserrat, B.W.I., at 1330 hours, June 2, 1961, on the lawn in back of a house. When discovered, the male was securely holding the female by the back of the neck and mating was consummated without this position being changed.

The mating behavior outlined here is similar to that of Ameiva exsul but differs from that of $\underline{A}$. chrysolaema, as described by Noble and Bradley (1933). Apparently, chrysolaema relinquishes its hold on the neck and grasps the flank of the female just before coitus.

Basilisks were never seen in any phase of courtship. Schmidt $(1914,1931)$ reporting on the mating behavior of $\underline{B}$. vittatus in captivity said that "der streifenbasilisk" fights bitterly for possession of the female and that mating was observed several times during the year. He also found that the male usually seized the female by the neck before attempting copulation.

\section{Nesting Locality}

No nests of either lizard were found. $s_{e} v e r a l$ observations, however, suggest that the eggs of both species are laid in the vegetated zones of the strand.

On July 11, 1960, a female Ameiva was found digging a hole in a pile of sand under a coconut tree in the cocal. 
She used her forefeet in the operation. The abdomen was noticeably distended, and apparently she was carrying eggs ready to be deposited. When first seen, the posterior half of the body was protruding from the hole, and her hind legs and to some extent her tall were acting as anchors. Every few seconds the front feet pushed sand up beneath the body. This was usually done alternately by each foreleg. After several minutes of this, a movement of the observer scared away the lizard. The hole was examined and found to be five inches in length with an opening 1-1/8" $1 / 2 "$, The deepest point was four inches below the surface.

This nest digging activity, if such it was, agrees with that described by Blair (1960) for Sceloporus olivaceus and with observations made by Dr. Archie Carr (personal communication) on Sceloporus undulatus.

On August 1, 1961, an adult female Ameiva with a distended abdomen was shot in the cocal. The stomach contained what appeared to be an egg of Basiliscus vittatus. The size and shape agreed well with oviducal eggs of the basilisk. If this Ameiva was in its normal area, then it can be considered evidence that basilisks lay their eggs in the cocal. A second find occurred on July 31, 1961, when Chuck Carr found what looked like another basilisk egg in the path next to a dense clump of cocoplum. Evidently, a sea turtle had uncovered the egg in the process of concealing her own egg nest. Although very similar to mature oviducal eggs of $\underline{B}$. vittatus, the two eggs discovered under these circumstances may have been those of snakes or even of Basiliscus plumifrons. 


\section{PARASITES AND PREDATORS}

The only ectoparasites found on Ameiva were red mites, Trombicula alfreddugesi. Seventy-five per cent of all beach lizards were infested. The mite was found on the lizards in eight different months, the heaviest infestation occurring in August and september. The parasites were predominately in the areas of the axilla and groin. Ameiva festiva was also infested similarly. Both species occasionally were noticed scratching themselves with the hind legs in areas of greatest infestation of mites. Mites were never found on Basiliscus vittatus or B. plumifrons. This may reflect the different behavioral patterns of the two genera, rather than host specificity of the parasite. Fitch (1956, 1958) found this same mite on an inguanid (Crotaphytus collaris) and a teild (Cnemidophorus sexlineatus) inhabiting the same area in Kansas.

Snakes are probably the most important predators of both species. In september, 1961, Ameiva were found in the stomachs of Clelia clelia and Dryadophis melanolomus collected in the cocal.

on the beach, ghost crabs may occasionally prey on lizards. In July, 1960, I found two ghost crabs eating Ameiva. In August, 1961, Chuck carr found a crab eating a juvenile Basiliscus. 
One adult female Ameiva was collected on a rainy day, August 1, 1961, in the cocal. As already mentioned in the section on Nesting Locality, the stomach of this lizard contained an egg similar to that of a basilisk. This may have been an abnormal meal because it had been raining the previous eight days, and the lizards were prevented from foraging.

On August 29, 1960, I witnessed the only case of cannibalism seen, when a large female Ameiva was found eating a juvenile in a clump of cocoplum on the beach. The s-v length of the victim was $45 \mathrm{~mm}$. The observation was made after four days of heavy rain.

of 250 beach lizards examined, 30 per cent had clearly lost part of their original tails. Twenty per cent of 185 juvenile basilisks and 33 per cent of 125 adult basilisks definitely were lacking part of their tails. Broken-off tails were more common in males of both species. Since Ameiva and juvenile Basiliscus are normally gregarious, the loss of tail could be attributed to predators. In adult basilisks, predators and intraspecific aggression are probably responsible for tail loss.

My observations seemed to show that Ameiva depends primarily upon speed to escape from enemies, while basilisks depend more upon concealment. This conclusion was based on observations of escape behavior prompted by my presence, however, and the behavior in the face of natural enemies may be different. 
STRUCTURE OF THE POPULATIONS

\section{Density}

The density of all lizards except mature Basiliscus vittatus was determined by marking and observation in 8.5 acres of beach and cocoplum habitat. Most of these data were obtained during home range studies. The study area was quite homogeneous throughout its length, and was judged favorable habitat for both species of lizards. Since adult basilisks are not found on the beach, the adjoining cocal was studied to determine their density. The study tract in this case also was 8.5 acres, but it included a variety of different habitats and conditions of illumination.

There never was a period when every lizard on the plot was marked, although it is believed that more than 80 per cent were accounted for at all times. The immigration of adults and the dispersal of young from other areas of higher population pressures may be responsible for the influx of unmarked individuals. On the other hand, marked individuals may have been lost to other areas for the same reasons.

The numbers of lizards recorded on the study area, at various times over a period of three years, are given in Tables 11 and 12. The density of juvenile beach lizards varied from 5.1 to 10.0 per acre. The same area supported an adult population of 6.9 to 15.8 individuals per acre. 


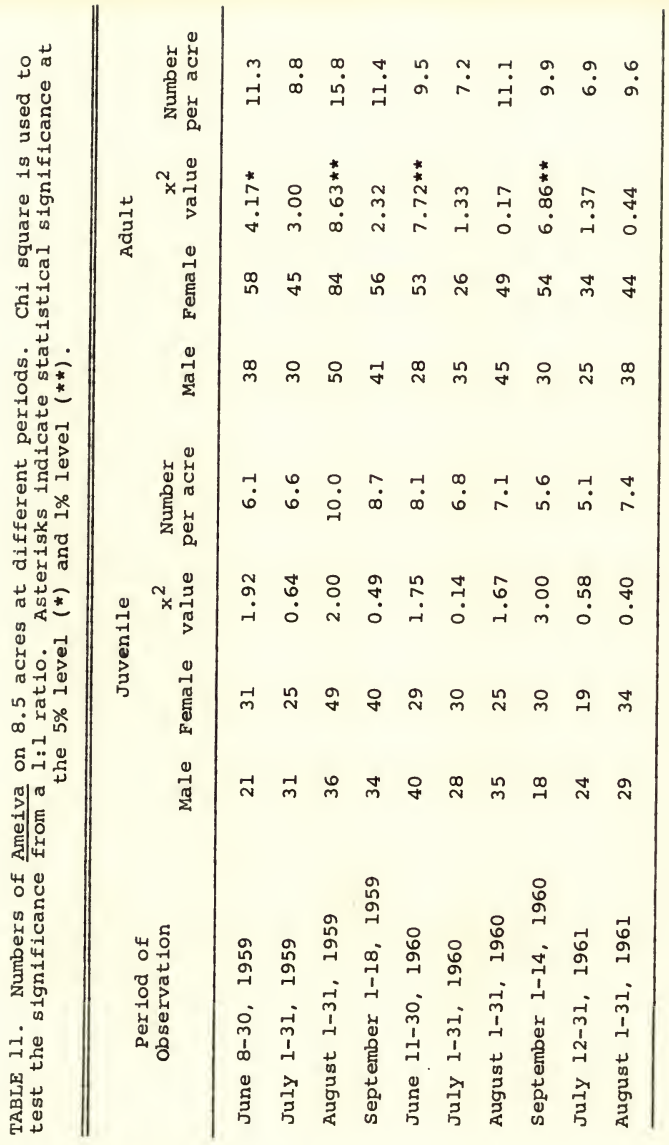




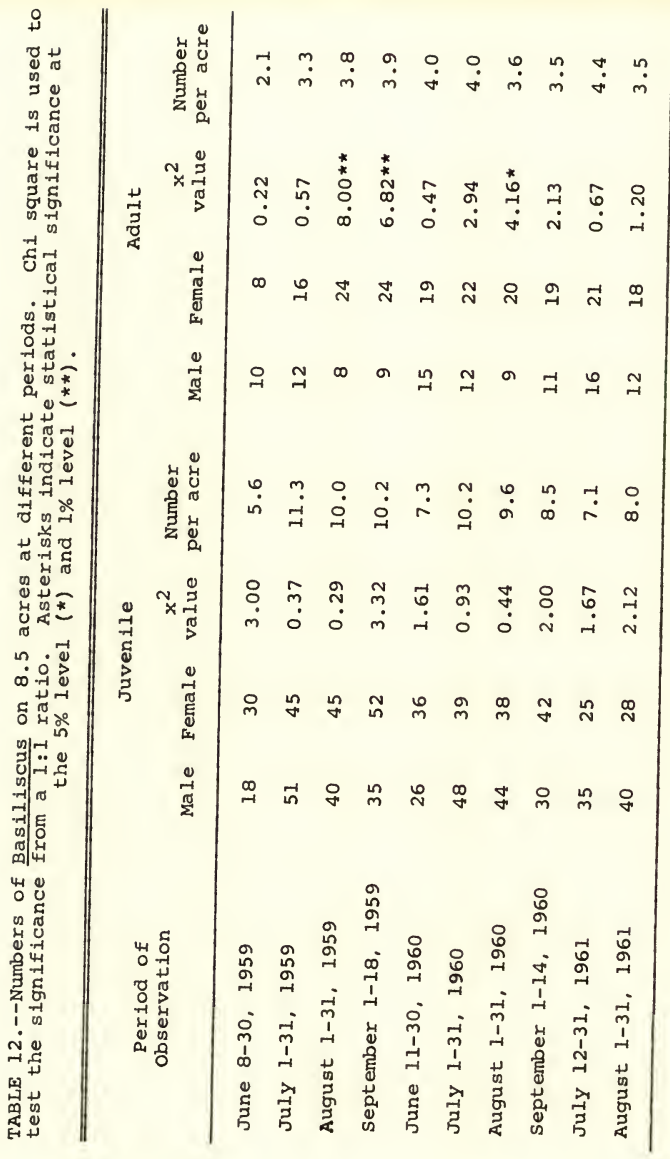


The combined numbers suggest a teid population of 12.0 to 25.8 lizards per acre. Since the numbers of juveniles and adults do not vary much from month to month, or, from year to year, it appears that the teidd population tends to maintain itself at a fairly constant level.

Numbers of juvenile basilisks varied from 5.6 to 11.3 per acre. Adult basilisks were recorded with much less frequency. Although Table 12 shows the crude density of adults to be 2.1 to 4.4 per acre, the ecological density would be at least double that because most of these animals were found only in the most suitable habitats of the study plot. The cleared land beneath the coconut trees and the riverbark are the favored terrain. Barden (1943b) estimated the population of Basiliscus basiliscus at Barro colorado Island, Canal Zone, in July and August, 1938, to be one lizard per 50 feet of shoreline.

The density of Ameiva might seem somewhat low, inasmuch as the habitat appears ideal for this heliophilic reptile, and the tropical environment offers relatively constant yearround living conditions. But, it must be remembered that for a brief time each morning the beach is shared with some of the juvenile basilisks, and the carrying capacity of the beach ecosystem is of course exploited by all lizards that are on the beach at the same time.

Juvenile beach lizards never represented more than 49 per cent of the total number of teiids on the beach during any period of observation. The number of juvenile basilisks 
always outnumbered the adults in adjacent but different habitats of the same size.

There were slightly more juvenile basilisks than juvenile beach lizards on the beach. This might be explained by the fact that young Ameiva has to compete with adults in the same habitat, whereas on this study area, young basilisks never compete with adults of their species.

\section{Sex Ratios}

Sex ratios of juvenile and mature lizards are shown in Tables 11 and 12. There were no significant differences in numbers of juvenile males and females of either species at any time during the study. Short collecting trips were made to the study area in January, February, March, and April. Although observations were few at these times, the sex ratios were similar to those reported in the tables, and in no set of data were there statistically significant departures from a 1:1 ratio. Among adults, the number of females far exceeded the number of males, and in several cases this difference was statistically significant (Tables 11 and 12).

These data indicate that the males of both species undergo heavy mortality when sub-adult. It has already been pointed out that the adult male Ameiva has no center of activity, and that its home range is larger than that of any lizard category studied. This greater activity on the part of the males probably exposes them to more attacks by predators, and this may bring the higher mortality. 
The preponderance of adult female basilisks may be explained, in part, by the relatively restricted home range of the male, particularly around coconut piles. Since the most frequent combinations of males and females around coconut piles are one male and one female, and one male and two females, it can be seen how females outnumber males on the same area. An alternative explanation for the low number of males might be that sub-adult males disperse some distance from their juvenile home range to avoid competition from males in established home ranges.

From these data the following conclusions may be drawn: (1) the populations of both Ameiva and Basiliscus tend to maintain relatively constant levels; (2) there is a greater attrition in the males in pre-adult life; (3) the adult females outnumber the males throughout at least part of the year; and, (4) the juvenile telids never represent more than 50 per cent of the total population of teidis on the beach at any time.

\section{Replacement of the Populations}

In the summer of 1960 a series of experimental plots was set up in order to determine what would happen to the densities of Ameiva and Basiliscus if one or the other species was absent from the beach.

Three equal and nearly homogeneous sections of the beach were marked off in the midale of the strand. Each plot was four acres in area and extended from the seashore to the cocoplum-seagrape hedge. The plots were separated from each 
other by four acres of undisturbed beach. Superficial observations indicated that all plots supported approximately equal numbers of 1izards. Between June 12 and June 23, all the teilds were removed from plot No. 1, all juvenile basilisks from No. 2, and all lizards of both kinds from No. 3 . The remaining lizards were marked by toe clipping and with colored string. Species, size, and sex of the lizards filling the empty niches were then systematically recorded. since the beach is relatively homogeneous throughout its extent, it is assumed that the populations of lizards throughout the beach habitat are similar. Therefore, in the following account, when reference to the normal number of $11 z-$ ards is made, this number can be estimated by referring to specific months in Tables 11 and 12 .

In september, 1960, approximately one-half the normal number of telids were back in Plot No. 1, one-third the normal number of basilisks were in No. 2, and similar proportions of each species were back in No. 3. There was no significant change in the numbers of each species left on the plots. In all cases, the first new individuals to appear were juvenile teilds of both sexes, and mature male teids. As already pointed out, these lizards show little or no attachment for a center of activity and have fairly large home ranges. Most of the newcomers probably came from the neighboring undisturbed areas, si nce early recaptures were near the shared borders. Later recapture sites in the new plots showed Ameiva working its way toward the seashore. When the lizards were frightened they ran into the adjoining areas, 
or back to the cocoplum hedge. The slower replacement of the basilisks may be a result of their breeding cycles, about which little is known. No changes in feeding behavior, growth rates, or size of home range were noted in the population left intact when one species was removed.

In July, 1961, the densities of each species on the experimental plots were similar to those in undisturbed habitats. At this time when the lizards were chased they usually tried to hide under logs or vegetation within the plot. This change in escape behavior suggested that they were familiar with the territory.

The above experiment suggests that teilds and basilisks act as separate populations on the beach and are capable of replacing themselves to the normal carrying capacity in one year or less. 


\section{LOCOMOT ION}

Neither Ameiva nor Basiliscus attains the high running speed characteristic of some lizards. However, both are capable of running for some distance. If surprised in the middle of the beach, some run directly to the cocoplumseagrape hedge, while others head for a log. Ameiva always runs quadrupedally, usually in a straight line, with the tail arched over the back. A young basilisk runs bipedally, at a slower speed, and over a more irregular course. Generally speaking, in both species, shorter runs (half the width of the beach, for example) are more frequently made than longer runs.

Adult basilisks were flushed many times in their natural habitat. They almost always made off with the bipedal form of locomotion. They are very agile when running in this manner, scampering off the top of coconut piles and skillfully dodging in-and-out among stems and branches. Adults were seen moving slowly in a quadrupedal gait while basking and feeding.

An attempt was made to measure maximum running speeds by chasing lizards down a strip of beach and timing them with a stop watch. The test took place on the beach, on a morning when cloud cover was $5 / 10$, and when sand and air temperatures were $32^{\circ} \mathrm{C}$ and $29^{\circ} \mathrm{C}$, respectively. The lizards 
were captured one to two hours before the test. Immediately before the run, they were allowed to thermoregulate until their body temperature reached a point in the normal activity range.

Ten beach lizards with s-v lengths of $60 \mathrm{~mm}$ to $70 \mathrm{~mm}$ and tails 185 to 195 per cent as long as the body were tested. The average speed at which five males covered a distance of 30 feet was $3.50( \pm 0.30)$ seconds $(5.8 \mathrm{mph})$. The mean speed of five females for the same distance was $4.0 \quad( \pm 0.22)$ seconds $(5.1 \mathrm{mph})$.

The average speed at which ten young basilisks, with $\mathrm{s}-\mathrm{v}$ lengths of $45 \mathrm{~mm}$ to $55 \mathrm{~mm}$ and tails about 260 per cent of $s-v$ length, ran bipedally over a distance of 20 feet, was computed at $3.8( \pm 0.31)$ seconds $(3.6 \mathrm{mph})$.

Five adult male basilisks with $\mathrm{s}-\mathrm{v}$ lengths of $90 \mathrm{~mm}$ to $110 \mathrm{~mm}$ and tail lengths of $250 \mathrm{~mm}$ to $315 \mathrm{~mm}$ ran the same distance as Ameiva in $3.4( \pm 0.19)$ seconds $(6.0 \mathrm{mph})$. Five females of comparable size ran the course in $3.5( \pm 0.34)$ seconds $(5.8 \mathrm{mph})$. It should be noted that the adults were forced to run on an extremely different substrate from that to which they are accustomed.

Adult basilisks can begin bipedal locomotion directly from a resting position. To learn whether the juveniles have the same ability, the front legs of 16 individuals were tied to the abdomen. Of 16 lizards, only half were capable of raising themselves and running a short distance.

In his studies of bipedal lizards, snyder (1949, 1954) found that the weight of the tall, used as a counterbalance, 
was the most important single factor in the capacity to run on two legs. He also demonstrated the importance of tail length, and found that adult Basiliscus basiliscus was unable to maintain the bipedal gait after the distal third of the tail was removed. Similar results were obtained in my study with adult $\underline{B}$. vittatus. An attempt was also made to determine the length of tail needed for bipedalism by young B. vittatus. Portions of the tail were surgically removed from ten juvenile basilisks ( $\mathrm{s}-\mathrm{v}$ and tail lengths of 40-50 mm and 98-130 mm). It was found that when $50.5( \pm 2.45)$ per cent of the tail was removed the lizards could not maintain the bipedal gait. As already mentioned, the tail grows proportionately faster than the body (Fig. 11). This is perhaps adaptively related to the need for a proportionately longer tail to carry out bipedalism as the body weight increases with age.

\section{Swimming}

Some beach lizards and many adult basilisks live in the cocal on the bank of the river. If pursued, basilisks enter the water freely, but the teilds invariably run into spaces among exposed roots of the overhanging bank.

observations on swimming behavior were obtained by forcing 15 teilds and basilisks to jump into the river. No differences in swimming behavior were observed between the sexes in either species. Both juvenile and adult teilds swim in a serpentine fashion, with all four legs pressed against the body and the tall fully extended. Before moving off this way, two were seen to use their front feet in a 
sort of padding motion, to get started. All lizards were capable of swimming the set distance of eight feet without stopping. All then climbed out of the water and scampered away .

The water-walking ability of basilisks is well known. Basiliscus plumifrons is the most adept at this, but $\underline{B}$. vittatus is also able to stay on the surface through short distances. Young basilisks were able to run a distance of one or two full strides on the surface of the water before sinking, after which they swam with a serpentine motion with all limbs pressed against the body. These basilisks did not appear to use the tail for a propelling force as much as the beach lizards did. All lizards swam a distance of six feet and then climbed out on the shore or on water hyacinths. one lizard used its hind legs in frog-fashion toward the end of the swim.

Adult basilisks are also capable of running on the water surface for two or three strides, and usually more. I could not determine the distance the adults swam underwater because they invariably swam under the riverbank or into dense mats of hyacinths. However, all were recorded as swimming at least ten feet underwater. 


\section{AGGREGATION}

General observations indicated that the lizards were not scattered randomly over the beach. A test of spatial distribution was made, following the procedures described by Dice (1952). A homogeneous section of the beach was divided into 50 quadrats 75 feet square. The number of quadrats in which $0,1,2 \ldots . . n$ lizards were observed was recorded. The test was conducted on a morning in August, in three different years. Weather conditions were similar each morning, and the census was conducted during the normal activity perlod of the lizards. All sizes of beach lizards, but only juvenile basilisks, were counted. The results are shown in Table 13 .

Dice (ibid.) states that if the variance is greater than the mean of the sample quadrat it indicates a tendency for the individuals to occur in aggregations. My results indicate that Ameiva is gregarious. Similarly, in two of the three tests with basilisks, an aggregation phenomenon is suggested. The tendency to occur in aggregations is typical in the young of many animals.

To determine the statistical significance of these tendencies toward aggregation, the chi square test was used. Table 13 indicates that two of the distributions of telids, 


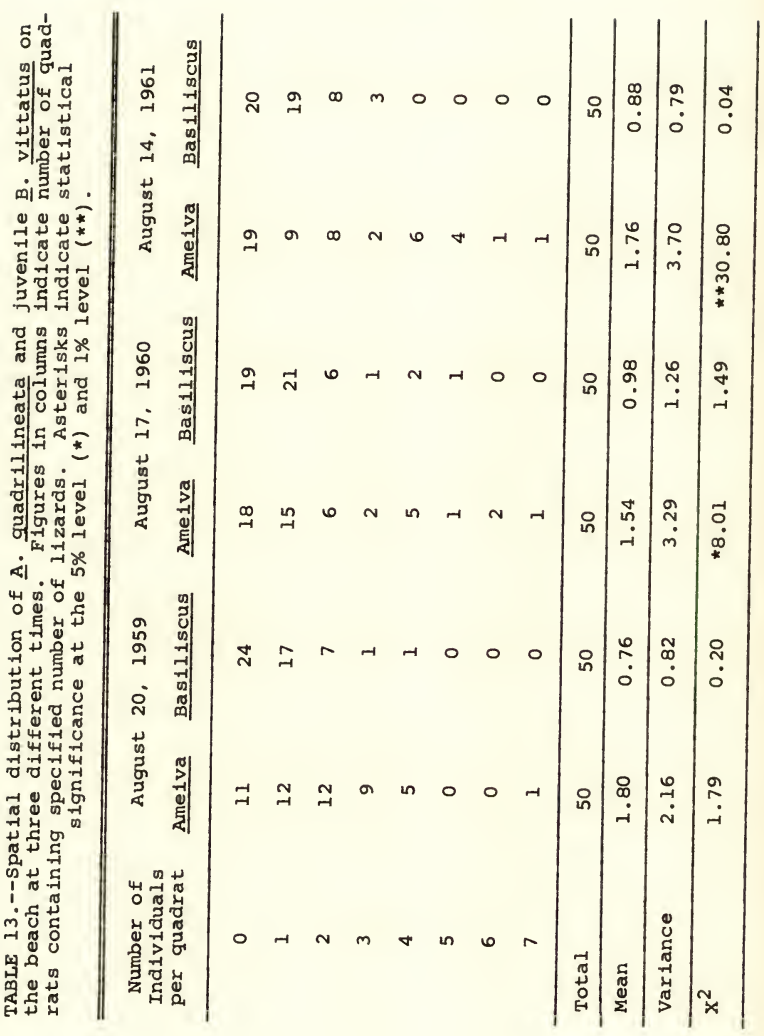


but none of the basilisk distributions, were statistically significant from the Poisson series.

Table 14 lists the most frequent combinations of beach lizards and basilisks found, using the same log at the same time for basking, feeding, or both. Data were collected in mid-morning over a two-mile stretch of beach. A total of 278 observations were made during a period of four months in 1959. Aggregations of the same species accounted for 74.1 per cent of the observations. The most common combinations were one and two beach lizards and one and two basilisks. Mixed aggregations were frequent on cloudy days. 


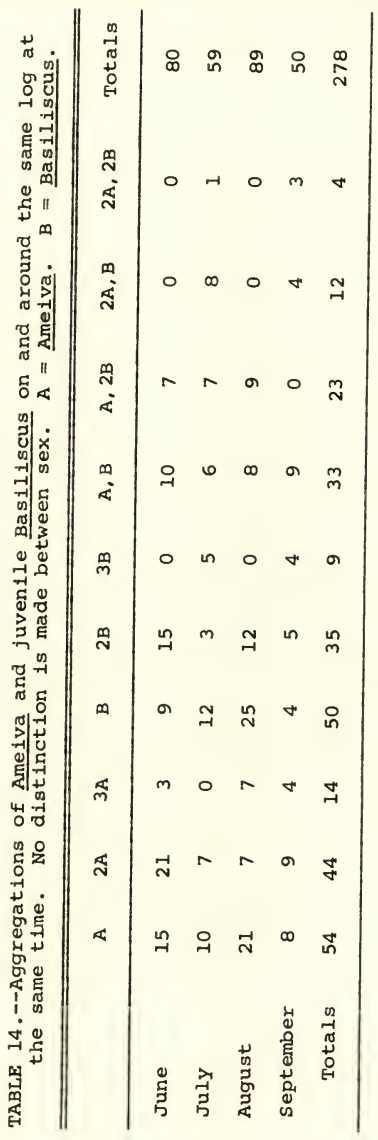




\section{SUCCESSION IN LIZARD POPULATIONS}

When a building site was cleared on the riverbank at the north end of the strand an opportunity to study a pattern of succession in lizard populations was provided. A census of lizards was taken before the land was cleared and repeated at various times during the next two years, while the new house was occupied and later when it had been abandoned. Each census was made in the morning, and at least five such inventories were made during each month of observation. The cleared area was a five acre expanse, and in it a total of 256 lizards were observed. Fig. 12 shows changes that occurred in the populations of lizards.

As the diagram indicates, Basiliscus vittatus and $\underline{B}$. plumifrons were the most common lizards on the site before the area was disturbed. During the actual construction period, the numbers of basilisks dropped and Ameiva became more abundant. The local laborers did not intentionally molest any lizard at any time. In september, 1959, at the height of construction activity, only one $\underline{B}$. plumifrons was seen. Other B. plumifrons had evidently left because all the vegetation on the riverbank was cut down. At the same time the teild population increased. Teilds were common around the building, in the new paths, and on the well-worn riverbank, while basilisks were most frequently seen basking 


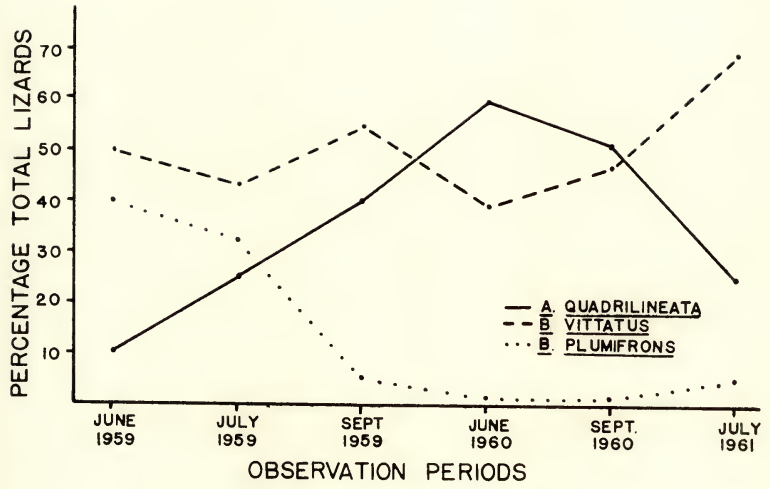

Fig. 12.--Changes in populations of lizards during the clearing, habitation, and abandonment of a homesite on the riverbank. The June, 1959, census was taken under natural conditions; and the September, 1959, census was made at the height of human activity and construct1on. From september, 1960, to July, 1961, the area was practically abandoned. 
on stumps left by felling operations. From september to June, human activity slowly subsided, and in June, 1960, there was only one guard living on the premises. Amelva was by far the most common lizard. From this time on no new land was cleared. The guard left in November, 1960, and the site remained undisturbed until the next summer. By July, 1961, the number of telids had decreased and $\underline{B}$. vittatus was the most abundant lizard. No juvenile basilisks were ever seen, although they were abundant on the adjoining beach. Thus, the pattern of succession showed numbers of beach lizards increasing with the original clearing, and then falling off when the area was abandoned and grasses started to overrun the site. During the period of human activity numbers of Basiliscus vittatus did not vary much but after abandonment of the camp they increased, probably because additional basking sites, in the form of tree stumps, were then available. Basiliscus plumifrons was, throughout the study, most abundant in the undisturbed area. After clearing had occurred it was never again seen in numbers. 


\section{OTHER ANIMALS ON THE BEACH:}

\section{THE BEACH AS AN ECOTONE}

As Carson (1955) stated, "To understand the shore, it is not enough to catalogue its life." She referred to the shore underwater, but the same can be said of the upper strand. In the following section, the activities of some of the more prevalent animals, and their roles in the beach ecotone, are discussed.

The sea turtles are the largest reptiles on the beach at Tortuguero. The green sea turtle (Chelonia mydas) emerges to lay eggs on the beach from June to october. The peak of the laying season is in July. The hawksbill (Eretmochelys imbricata), loggerhead (Caretta caretta), and leatherback (Dermochelys coriacea) nest sporadically throughout the rest of the year, with peaks generally between May and November. The beach sand is also used as an incubating medium by the iguana (Iguana iguana). In March and during the first part of April, these big lizards climb down from their perches in the high trees, and move out to the beach to lay their eggs in the sand. Oviposition takes place in the early morning or late afternoon when the sand temperatures are relatively low. A series of gravid females collected between March 22 and April 1 had an average s-v length of $35.3 \mathrm{~cm}$ and an average of 35.5 oviducal eggs ready to be deposited. 
After hatching, the young disperse to the cocal where they are common among the undergrowth in the late summer. This is the reverse of the situation in Basiliscus vittatus in which the eggs are probably laid in the cocal and the young disperse to the beach.

The most serious predators on iguanas, turtles, and their eggs, are man and dogs. The ever-present vultures (Cathartes aura and Coragyps atratus) clean up whatever is left on the beach by the more active predators.

A number of boas (Constrictor constrictor) were found coiled on logs on the beach at night. Eight individuals (average total length $57.5 \mathrm{~cm}$ ) were found in July and August. One snake regurgitated a mouse. Mice are abundant under the drift logs.

The most abundant amphibian on the beach is the large toad, Bufo marinus. It is most common at night sitting on or around logs. Chuck Carr and I found amphipods in three of ten toad stomachs examined.

Termites have extended their habitat to include parts of the beach. Not only are they common in every decaying log, but they have even built good-size mounds on the beach itself.

Next to the insects, the dominant and most conspicuous invertebrates are crabs. Three species are found, in moreor-less definite zones across the strand. The ghost crab (ocypode quadratus) is the most abundant form. It is most frequently seen feeding among the tidal wrack at night but can also be seen in the morning on overcast days. It is 
likely that it eats amphipods, together with organic debris, in the drifted water hyacinths. An attempt to verify this by examination of stomach contents was unsuccessful because the food had been masticated beyond recognition. However, Crane (1941) found amphipods in the digestive tracts of Ocypode occidentalis (the Pacific coast analogue of quadratus). Another crab, Gecarcinus lateralis is common under logs, coconut husks, and planks on the beach and in the cocoplum-seagrape hedge. A third, Cardisoma guanhumi is fairly abundant on the riverbank. Dansereau (1947) described a similar zonation of crabs on the halosere of eastern Brazil.

When Ameiva and Juvenile Basiliscus are being chased they go down crab burrows, but only as a last resort. ocypode has been observed eating teilds and basilisks on the beach. Whether it caught these or found them dead is not known.

Some animals, notably snakes and freshwater turtles among the vertebrates, are stranded on the beach when rafts of hyacinths pile up there in the rainy season. The ecologic role of these accidental arrivals in the beach community remains to be determined.

In summary it may be stated that during the day the dominant members of the strand association are lizards and insects, while at night, turtles, toads, and crabs are the most active occupants.

Sea turtles and ghost crabs provide a good example of biotic relations in an ecotone. The crabs occupy burrows on 
the beach but occasionally need to dip into the sea to replenish water in the branchial chambers surrounding the gills. The females also enter the water to liberate their young. The juveniles crawl back on the beach during the megalops stage. The air-breathing turtles use the beach in a different way, living in the water all their juvenile and adult life, but returning to the beach to lay eggs. After an incubation period of about two months, the young turtles hatch and crawl to the sea. The males never return to land and the females come back only every two or three years to deposit their eggs. This relationship between crabs and turtles on sandy beaches was commented on by Hedgpeth (1957). among others.

One of the important aspects of the ecology of Ameiva and Basiliscus is their reliance on beach amphipods as food. Such a situation, with predominantly terrestrial lizards feeding on a group of organisms whose ancesters were completely marine, seems graphically illustrative of the kind of factor involved in the so-called edge-effect in ecotonal habitats.

Another ramification of ecotone organization, and in itself an impressive sight, is the coming of large, pregnant iguanas to the beach to deposit their eggs. Here is a case in which a preeminently arboreal lizard leaves its perch high in a tree on the riverbank and crawls through a dense stand of undergrowth to dig its egg nest on an open shore of sea-sand. The sixteenth century historian oviedo 
(see Stoudemire, 1959) suggested the unique attributes of this reptile when he said, "The natives also eat a kind of serpent that is very fierce and fearful to look upon but is entirely harmless. It is not certain whether this is an animal or fish, since it lives in the water, in trees, and on the ground." The turtles leave their home in the sea, and the iguanas leave their home in the trees to rendezvous once a year on the beach at Tortuguero.

These are only a few examples showing how terrestrial and marine animals intermingle on the beach. Some land antmals patrol the seashore to feed, and some marine animals are drawn to the beach to breed and live. Needless to say, the beach also has its own characteristic animal life, and this, of course, is also characteristic of the ecotone. Pearse (1950) discusses the role the beach has played in the emigration of animals from sea to land. 


\section{DISCUSSION}

Gause's rule or, as it has recently been termed, the "competitive exclusion principle" (Hardin 1960), states that two species cannot permanently occupy the same ecological niche. Although this concept has been accepted by most zoologists, the ecological niche is very hard to define and analyze because it encompasses all the activities of an animal in relation to the biotic and physical environment. study of the niche concept is most practicable in early successional situations, or where factors approach limiting values, and where organization is thus held at the survival level of complexity. The arctic tundra is an example of such a situation; the tropical strand is another.

In an extension of Gause's rule, Hairston (1959) said, "The organization of a community results from the outcome of interspecific competition for the available resources, and is expressed both in the relative abundance and the spatial distribution of the constituent species." In the light of such views on competitive niche occupancy, it is of interest to examine the roles and relations of Tortuguero lizards in as fine detail as data permit. The discussion on niche occupancy which follows pertains chiefly to the teilds and juvenile basilisks found on the beach. The chief factors to 
be considered are habitat distribution, home range, feeding habits, and activity cycles.

Teiids of all sizes are most abundant on the beach but are also common in open, sunny areas throughout the cocal. Juvenile basilisks are usually seen only on the beach, while adults are found only in the cocal and in the cocoplumseagrape hedge.

Both species are diurnal, heliophilic lizards, most active on the beach during warm, clear mornings. The home ranges of juvenile Ameiva, adult Ameiva, and juvenile Basiliscus overlap extensively on the beach. The home ranges of both species are irregular in shape and extend from the seashore to the cocoplum-seagrape hedge, and sometimes into the cocal. In many cases the same logs within the home range are used by both species for thermoregulatory and feeding purposes. Likewise, the same plants may provide cover for both species. During the dry season the home ranges of both lizards are smaller, and more activity takes place in the vegetated zones of the strand. In contrast to the home range of juveniles on the beach, that of the adults in the cocal is more or less circular and is usually centered around a coconut pile or other favorite basking perch. All data indicate that neither Ameiva nor juvenile Basiliscus maintains territory on the beach, although indirect evidence indicates that in the cocal the adult basilisks may maintain territories. Intraspecific, and to some extent intergeneric, aggregations were noted in the teild and basilisk populations on the beach. This suggests that there is no 
antagonism between the lizards even while the same, or a closely similar, niche is shared.

In determining the niche of an animal, its feeding habits assume great importance. Both Ameiva and juvenile Basiliscus depend chlefly upon sight to obtain food. Both prey upon the same insects and crustaceans, and the size of the prey taken is the same. During the rainy season amphipods, darkling beetles, lycosid spiders, and grasshoppers are the most common prey taken by both species. These forage species constituted 69.6 per cent of the total food items eaten by 244 telids and 69.9 per cent of the total food items eaten by 110 basilisks. In the dry season food habits are also similar, except that amphipods are lacking from the diet. No differences in food preferences were found between the sexes in either species. The diets do differ to some extent, however, in that Ameiva eats more larvae than Basiliscus, while the latter takes more flying insects. As the bastlisks grow and move off the beach they eat larger prey, more flying insects, and some vegetation; and ants take the place of amphipods as the most important food item.

Seventy-five per cent of the food items eaten by teids were from $3.1 \mathrm{~mm}$ to $9.0 \mathrm{~mm}$ in length, while 82 per cent of the juvenile basilisks' food was in this size-category. This is evidence that when both species are on the beach they compete directly for food. Direct competition is lessened, however, by different methods of feeding. Ameiva moves about pushing its head along in a grubbing fashion, 
but Basiliscus usually sits motionless on a $\log$ and waits for insects to crawl or alight nearby. These differences in feeding behavior evidently explain why the teilds take more larvae and the basilisks more flying insects.

There appears to be one factor that separates the roles of the two lizards and prevents complete competition. This is the temperature-relations of the two. Because they are ectotherms with different thermal tolerances, they do not occupy the niche on the beach at the same time. The ecological optimum temperature of Ameiva, based on 556 records, is $37.6^{\circ} \mathrm{C}$; that of juvenile Basiliscus, based on 322 records, is $35.3^{\circ} \mathrm{C}$. On sunny days the greatest number of basilisks appear, and are active, on the beach in the early morning. As ambient temperatures rise, the basilisks are replaced by the teilds. There is, of course, a period of overlap, when some individuals of both species are on the beach together. The length of this period depends upon weather conditions. On sunny days the period of overlap is short, but on overcast days some individuals of both species may spend the greater part of the morning on the beach.

At this point in the discussion, mention should be made of the bearing of results of the present study upon other studies on temperature tolerances among lizards. cloacal temperatures of Ameiva quadrilineata from the beach at Tortuguero; of Ameiva festiva from the forests at Tortuguero; and of Ameiva pluvianotata from the beach at Montserrat, B.W.I., were taken. Body temperatures of Basiliscus vittatus on the strand, and of Basiliscus plumifrons on the riverbank, 
both at Tortuguero, were also taken. The results tend to support Bogert's generalizations (1949a, 1949b, 1959) that congeneric lizards tend to have similar, but not necessarily identical, thermal preferences even though they live in different habitats and climatic regions. Although the thermal optima of Ameiva quadrilineata $\left(E O=37.6^{\circ} \mathrm{C}\right)$ and 스. estiva $\left(\mathrm{EO}=36.2^{\circ} \mathrm{C}\right)$ and those of Basiliscus vittatus $\left(\mathrm{EO}=34.7^{\circ} \mathrm{C}\right.$ ) and $\underline{B}$. plumifrons $\left(E O=31.7^{\circ} \mathrm{C}\right)$ are statistically different, this is not construed to be of any great ecological significance. As Bogert (1949a) mentions, body temperatures of reptiles are a result of the interactions of habit and habitat. Since the various species of teilds and basilisks reported on here have similar habits, it is logical that the species living in the more dense habitats should have slightly lower temperature tolerances. Ectothermy necessitates a close adjustment to the environment. of special interest is the fact that $\underline{A}$. quadrilineata and $\underline{A}$. pluvianotata $\left(E O=37.8^{\circ} \mathrm{C}\right)$ occupying similar, but widely distant, habitats, do have very similar thermal preferences. Moreover, although juvenile and adult basilisks act as ecologically separate populations in adjacent but different habitats, they have very similar thermal thresholds.

Thus the results of this study appear to support the general concept of Bogert (ibid.) and other workers, that temperature tolerances have remained conservative through the evolutionary history of lizards. As already mentioned, the optimal temperatures of congeners in different habitats are similar. The difference between the ecological optimum 
of $\underline{A}$. quadrilineata and $\underline{A}$. festiva was only $1.4^{\circ} \mathrm{C}$; that between adult $\underline{B}$. vittatus and $\underline{B}$. plumifrons was $3.0^{\circ} \mathrm{C}$. These differences are in accord with what one would expect if evolutionary changes in thermal tolerances were slow. In his work on the Cuban species of Anolis, Ruibal (1961) appears to have found an exception to this general concept. His results suggest that perching habits have remained conservative within related species, while the thermal habitat selected, or temperature preference, has diverged.

Besides their different temperature preferences, Ameiva and Basiliscus populations in the cocal show another sort of ecological divergence. This is the character of the basking areas. As a result of numerous observations made throughout the study it appeared that one of the chief proximate limiting factors for Ameiva quadrilineata was open, sunny, baresand surfaces. Similarly, one of the most important limiting factors for Basiliscus vittatus appeared to be availability of exposed basking perches. It is interesting to note that both these limiting factors are closely related to thermoregulation.

In summary, it may be stated that Ameiva quadrilineata and juvenile Basiliscus vittatus evidently occupy closely similar ecological niches on the beach at Tortuguero. Direct competition for this niche is reduced, however, by a difference in thermal preferences, because of which the majority of lizards of each species are never active on the beach at the same time. Moreover, when telids and basilisks are on the beach together, even though diets of the two are closely 
similar, direct competition for food is reduced by their different methods of feeding. No doubt, other subtle differences help reduce competition. Thus, although superficial appraisal suggests that the two Tortuguero lizards have identical ecologic roles, a closer scrutiny reveals definite ecesic insulation between them. The study therefore in no way impugns the validity of Gause's rule. 


\section{SUMMARY AND CONCLUSIONS}

The ecology and behavior of two lizards, Ameiva quadrilineata Hallowell (Teiidae) and Basiliscus vittatus Wiegmann (Iguanidae) were studied under natural conditions on the strand at Tortuguero, on the Caribbean coast of costa Rica. Observations and collections were made during eight different months, for a total of 310 days, from June, 1959, to september, 1961 .

The strand at Tortuguero can be divided into three major vegetation zones: (1) the beach, where most of the plant-cover is provided by railroad vine, Ipomoea Pes-Caprae; (2) a salt resistant hedge made up chiefly of cocoplum, Chrysobalanus icaco and seagrape, Coccolobis uvifera; and, (3) a coconut grove (cocal) in which coconut palm, cocos nucifera is dominant in both the understory and the canopy.

Light intensity ranges from 9,500 foot-candles on the beach to 400 foot-candles in the cocal. The average diel maximum and minimum air temperatures on the beach are $30.5^{\circ} \mathrm{C}$ and $21.0^{\circ} \mathrm{C}$; those in the cocal are $29.0^{\circ} \mathrm{C}$ and $23.5^{\circ} \mathrm{C}$. The substrate in all the zones is fine to medium, olive-gray sand.

All size-groups of Ameiva are most common on the beach and in the cleared areas of the cocal. Juvenile and adult basilisks act as ecologically separate populations, living 
in adjacent, but different, habitats. The young are most abundant on the beach and in the hedge row, while adults are found only in the hedge row and in the cocal.

The activity cycles of both lizards are dominated and controlled by thermoregulatory needs, and are interrupted by periods of rain. The largest number of lizards are seen on clear, warm mornings. Ame1va and juvenile Basiliscus appear to occupy closely similar ecological niches on the beach, but their activity periods are separated by their different thermal tolerances. Adult basilisks do not have as welldefined activity periods as the juveniles.

The various thermal categories were determined on the bases of temperature records from 698 teiids, 476 juvenile basilisks, and 242 adult basilisks. No differences between sexes were found. Ameiva and Basiliscus have maximal diel temperature-cycles with amplitudes of $18.0^{\circ} \mathrm{C}$ and $14.5^{\circ} \mathrm{C}$, respectively. The ecological optimum temperatures of Ameiva, juvenile Basiliscus, and adult Basiliscus are, respectively, $37.6^{\circ} \mathrm{C}, 35.3^{\circ} \mathrm{C}$, and $34.7^{\circ} \mathrm{C}$. The critical maxima are: Ameiva, $45.1^{\circ} \mathrm{C}$; young Basiliscus, $42.8^{\circ} \mathrm{C}$; and mature Basiliscus, $43 \cdot 1^{\circ} \mathrm{C}$.

Reflectivity curves from lizard integuments and from sand of the substrate were taken. These suggested a close correlation between thermoregulation and concealing coloration. The function of the black peritoneal lining in the basilisks is not known, but may be connected with thermoregulation. 
The thermal optima of Ameiva festiva and Basiliscus plumifrons from the environs of Tortuguero, and of Ameiva pluvianotata from the island of Montserrat, B.W.I., were determined. The data support the suggestions of other workers that congeners in different or similar habitats tend to have comparable thermal preferences, while unrelated forms living together may show significant thermal divergence.

Both species of lizards depend chiefly upon sight in finding food. The stomach contents of 244 teilds, $110 \mathrm{ju}$ venile basilisks, and 210 adult basilisks, all collected during the rainy season, were examined. Amphipods, darkling beetles, lycosid spiders, and grasshoppers were the four most common food items eaten by Ameiva and juvenile Basiliscus on the beach. The size of the prey taken by the two lizards likewise was the same. However, direct intergeneric competition for food is reduced by the different methods of feeding. In the dry season amphipods are lacking from the diets of the lizards, evidently because of the dearth of tidal wrack at that time. In the cocal, ants, darkling beetles, and grasshoppers are the major food of adult basilisks. The digestive tracts of 42 adult basilisks contained vegetable matter while only two stomachs of Ameiva and juvenile Basiliscus contained vegetation.

To study home range and centers of activity, a total of 215 beach lizards, 160 juvenile basilisks, and 100 adult basilisks were marked by toe clipping. Seventy per cent of the teilds and 60 per cent of the basilisks were recaptured from one to 24 times. The home ranges of the species and 
age groups overlap extensively on the beach. Juvenile male and female Ameiva have home ranges which correspond to a square 50 to 54 feet on a side. As the teids mature, the males almost double the size of their home range while the females become more restricted in their movements. Juvenile female basilisks have the smallest home range of any lizard inhabiting the beach. The home ranges of adult male and female basilisks are similar, while those of adult Ameiva are statistically different. Adult female Ameiva have a welldefined center of activity while adult males do not. Adult basilisks show strong attachment for a favored basking site. The size of the home range varies in the dry and wet seasons and with the configuration of the shoreline.

Males of both species grow slightly faster than females. Sexual maturity is reached in less than a year, and the ecological longevity is probably less than a year. Some breeding may take place the year around, but the largest numbers of young lizards of both kinds are seen in August and september.

In basilisks, an ontogenetic change in tail length was correlated with assumption of bipedal locomotion.

Ameiva, but not Basiliscus, was found to be infested with trombiculid mites. Snakes are probably the most important predators.

Density estimates made over a period of three years indicated that populations remained fairly stable. The numbers of juvenile beach lizards varied from 5.1 to 10.0 per acre, and the numbers of adults varied from 6.9 to 15.8 per 
acre. The numbers of juvenile basilisks in the same area varied from 5.6 to 11.3 per acre. Adult basilisks are found only in certain sections of the cocal and their estimated density of 2.1 to 4.4 per acre is lower than the ecological density. There were no significant differences in the numbers of juvenile males and females of either species, but adult females outnumbered adult males.

Intraspecific, and to some extent intergeneric, aggregational tendencies were noted both among lizards active on the beach and when joint use was made of logs for feeding and basking. Heterosexual combinations of adult basilisks were common on coconut piles, but two males were never seen together.

As more land is cleared in the cocal, providing more open, sunny, bare-sand surfaces, the Ameiva probably will increase in number.

To elucidate the ecotonal nature of the beach, some activities of sea turtles, iguanas, crabs, and toads, all at one time or another important members of the community, are discussed. 


\section{LITERATURE CITED}

Allen, P. H. 1956. The rain forests of Golfo Dulce. Gainesville: Univ. Fla. Press. 417 pp.

Banta, B. H. 1957. A simple trap for collecting desert reptiles. Herpetologica 13: 174-176.

Barden, A. 1943a. Food of the basilisk lizard in Panama. Copeia (2): 118-121. - 1943b. Notes on the basilisk at Barro Colorado Island, Canal Zone. Ecology 24: 407-408. Beebe, W. 1945. Field notes on the lizards of Kartabo, British Guiana and Caripito, Venezuela. III. Teildae, Amphisbaenidae and Scincidae. Zoologica (New York) 30: $7-32$.

Blair, W. F. 1960. The rusty lizard; a population study. Austin: Univ. Texas Press. 185 pp.

Bogert, C. M. 1949a. Thermoregulation in reptiles, a factor in evolution. Evolution 3: 195-211. - 1949b. Thermoregulation and eccritic body temperatures in Mexican lizards of the genus Sceloporus. An. Inst. Biol. 20: 415-426. - 1959. How reptiles regulate their body temperature. Sci. Amer. 200: 105-120.

Boyce, S. G. 1954. The salt spray community. Ecol. Monogr. 24 : $29-67$. 
Brattstrom, B. H., \& N. B. Adis. 1952. Notes on a collection of reptiles and amphibians from Oaxaca, Mexico. Herpetologica 8: 59-60.

Brattstrom, B. H., \& T. R. Howell. 1954. Notes on some collections of reptiles and amphibians from Nicaragua. Herpetologica 10: 114-123.

Brues, C. T.. A. L. Melander, \& F. M. Carpenter. 1954. Classification of insects. Bull. Mus. Comp. Zool. 108: $1-917$.

Bundy, R. E., \& J. Neess. 1958. Color variation in the round-tailed horned lizard, Phrynosoma modestum. Ecology 39: 463-477.

Cagle, F. R. 1946. A lizard population on Tinian. Copeia (1) : 4-9.

Caldwell, D. K., L. H. Ogren, \& L. Giovannoli. 1959. Systematic and ecological notes on some fishes collected in the vicinity of Tortuguero, Caribbean coast of costa Rica. Rev. Biol. Trop. 7: 7-33.

Carr, A., \& H. Hirth. 1962, in press. The ecology and migrations of sea turtles, 5. Comparative features of isolated green turtle colonies. Amer. Mus. Novitates. Carr, A., \& L. Ogren. 1960. The ecology and migrations of sea turtles, 4. The green turtle in the caribbean sea. Bul1. Amer. Mus. Nat. Hist. 121: 1-48.

Carson, R. 1955. The edge of the sea. Boston: Houghton Mifflin Co. $276 \mathrm{pp}$.

Cobley, L. S. 1956. An introduction to the botany of tropical crops. New York: Longmans, Green and co. 357 pp. 
Cole, L. C. 1943. Experiments on toleration of high temperature in lizards with reference to adaptive coloration. Ecology 24: 94-108.

Comstock, J. H. 1948. The spider book. Revised and edited by w. J. Gertsch. Ithaca, N.Y.: Comstock Publ. Co. Inc. $729 \mathrm{pp}$.

Conant, R. 1951. Collecting lizards at night under bridges. Copeia (1): 79-80.

Cott, H. B. 1957. Adaptive coloration in animals. London: Methuen and Co. Ltd. 508 pp.

Cowles, R. B., \& C. M. Bogert. 1944. A preliminary study of the thermal requirements of desert reptiles. Bull. Amer. Mus. Nat. Hist. 83: 265-296.

Crane, J. 1941. On the growth and ecology of brachyuran crabs of the genus ocypode. Zoologica 26: 297-310. Dansereau, P. 1947. Zonation et succession sur la restinga de Rio de Janeiro. - I. Halosère. Contrib. Inst. Biol. Générale et Zool. Univ. Montréal, Canada. No. 20: 448-477.

Dice, L. R. 1952. Natural communities. Ann Arbor: Univ. Mich. Press. 547 pp.

Fitch, H. S. 1940. A field study of the growth and behavior of the fence lizard. Calif. Univ. Publ. Zool. 44: 151-172.

- 1951. A simplified type of funnel trap for reptiles. Herpetologica 7: 77ø80. 
- 1956. An ecological study of the collared lizard (Crotaphytus collaris). Univ. Kansas Publ. Mus. Nat. Hist. 8: 213-274.

- 1958. Natural history of the six-lined racerunner (Cnemidophorus sexlineatus). Univ. Kansas Publ. Mus. Nat. Hist. 11: 11-62.

Gadow, H. 1909. Amphibia and reptiles. The Cambridge Natural History. Vol. 8. London: Macmillan and co., Ltd. $668 \mathrm{pp}$.

Grant, c. 1931. Notes on the Ameivas of Porto Rico. Copeia (2): 61-62.

Gunther, A. C. L. G. 1885-1902. Blologia Centrali-Americana; Reptilia and Batrachia. $326 \mathrm{pp}$.

Hairston, N. G. 1959. Species abundance and community organization. Ecology 40: 404-416.

Hald, A. 1952. Statistical tables and formulas. New York: John Wiley \& Sons, Inc. $97 \mathrm{pp}$.

Hallinan, T. 1920. Notes on lizards of the Canal zone, Isthmus of Panama. Copeia (83): 45-49. Hardin, G. 1960. The competitive exclusion principle. Science 131: 1292-1297. Haynes, B. C. 1947. Techniques of observing the weather. New York: John Wiley \& Sons, Inc. 272 pp. Hedgpeth, J. W. 1957. Sandy beaches. in Treatise on Marine Ecology and Paleoecology. Vol. 1. Ecology. J. W. Hedgpeth, ed. Geol. Soc. Amer. Memoir 67: 587-608. 
Holdridge, L. R. 1959. Mapa ecologico de Costa Rica, A. C. Preparado y publicado por el Instituto Interamericano De Ciencias Agricolas de la Organización de Estados Americanos (O.E.A.). Proyecto 39- Programa de Cooperacion Tecnica. San José, Costa Rica.

Hotton, N. III. 1955. A survey of adaptive relationships of dentition to diet in the North American Iguanidae. Amer. Midland Nat. 53: 88-114.

Hunsaker, D. II, \& C. Johnson. 1959. Internal pigmentation and ultraviolet transmission of the integument in amphiblans and reptiles. Copeia (4): 311-315. Hutchison, V. H., \& J. L. Larimer. 1960. Reflectivity of the integuments of some lizards from different habitats. Ecology 41: 199-209.

Inger, R. F. 1959. Temperature responses and ecological relations of two Bornean lizards. Ecology 40: 127-136. Johnson, D. W. 1919. Shore processes and shoreline development. New York: John Wiley \& Sons, Inc. 584 pp. Klauber, L. M. 1939. Studies of reptile life in the arid southwest. Bull. Zool. Soc. San Diego. 14: 1-100. Kruger, P., \& H. Kern. 1924. Die physikalische und physiologische Bedeutung des Pigmentes bei Amphibien und Reptilien. Pflugers Arch. Physiol. 202: 119-138. Leon, J. 1952. Nueva geografía de Costa Rica. 10 th. Edición Revisada. Librería La Española. San José, Costa Rica. 
Mertens, R. 1934. Die Insel-Reptilien, ihre Ausbreitung, Variation, und Artbildung. Zoologica (stuttgart) 32 : 1-209.

Mohr, E. C. J., \& F. A. Van Baren. 1954. Tropical soils. New York: Interscience Publishers, Inc. 498 pp. Mount, R. H. 1961. The natural history of the red-tailed skink, Eumeces egregius Baird. Ph. D. Dissertation, Univ. Florida.

Neill, W. T. 1958. The occurrence of amphibians and reptiles in saltwater areas, and a bibliography. Bull. Marine Sci. Gulf and Caribbean. 8: 1-97. Neill, W. T., \& R. Allen. 1959. Studies on the amphibians and reptiles of British Honduras. Publ. Research Div. Ross Allen Reptile Inst. Inc. 2: 1-76.

Noble, G. K., \& H. T. Bradley. 1933. The mating behavior of lizards; its bearing on the theory of sexual selection. Ann. New York Acad. Sci. 35: 25-100.

Norris, K. S. 1953. The ecology of the desert iguana Dipsosaurus dorsalis. Ecology 34: 265-287.

Oliver, J. A. 1937. Notes on a collection of amphibians and reptiles from the state of Colima, Mexico. Occ. Pap. Mus. Zool. Univ. Mich. No. 360: 1-28.

- 1955. The natural history of North American amphibians and reptiles. Princeton: D. Van Nostrand Co., Inc. $359 \mathrm{pp}$.

Pearse, A. S. 1950. The emigrations of animals from the sea. Dryden, N.Y.: Sherwood Press. 210 pp. 
Pearson, K. 1914. Tables for statisticians and blometricians. Cambridge: Cambridge Univ. Press. 143 pp. Peters, J.A. 1954. The amphibians and reptiles of the coast and coastal Sierra of Michoacán, Mexico. Occ. Pap. Mus. Zool. Univ. Mich. No. 554: 1-37.

Pittier, H. 1957. Ensayo sobre plantas usuales de Costa Rica. Segunda edición revisada. Serie Ciencias Naturales No. 2. Univ. Costa Rica, San José.

Raunkiaer, C. 1934. The life forms of plants and statistical plant geography; being the collected papers of $\mathrm{c}$. Raunkiaer. Oxford: Clarendon Press. $632 \mathrm{pp}$. Ruibal, R. 1961. Thermal relations of five species of tropical lizards. Evolution 15: 98-111.

Ruthven, A. S. 1912. The amphibians and reptiles collected by the University of Michigan-Walker Expedition in southern Vera Cruz, Mexico. Zool. Jahrb., Syst. 32: 295-332.

Sapper, K. 1932. Climatology of Central America. (English translation by U.S. Army Air Corps Weather Service). Handbuch der Klimatologie, ed. by W. Köppen and $\mathrm{R}$. Geiger. Vol. 2, Part H. Berlin: Gebrueder Borntraeger. Schmidt, P. 1914. Der Helmbasilisk (Basiliscus americanus Laur.) und eintges aus dem Gefangenschaftsleben der Basilisken im allgemeinen. Wochenschr. Aquar.-Terrar.Kde. 11: 362-363.

- 1931. Der Streifenbasilisk (Basiliscus vittatus Wiegmann). Wochenschr. Aquar.-Terrar.-Kde. 28: 5-7. 
Slud, P. 1960. The birds of finca "La Selva," Costa Rica:

a tropical wet forest locality. Bull. Amer. Mus. Nat. Hist. 121: 49-148.

Small, J. K. 1933. Manual of the Southeastern Flora. Chapel Hill: Univ. North Carolina Press. 1554 pp. - 1938. Ferns of the Southeastern states. Lancaster, Pa.: Science Press. 517 pp.

Smith, P. W., H. M. Smith, \& J. E. Werler. 1952. Notes on a collection of amphibians and reptiles from eastern Mexico. Texas Jour. Sci. 4: 251-260.

Snyder, R. C. 1949. Bipedal locomotion of the lizard Basiliscus basiliscus. Copeia (2): 129-137. - 1954. The anatomy and function of the pelvic girdle and hindlimb in a lizard locomotion. Amer. Jour. Anat. 95: 1-45.

Standley, P. C. 1937-8. Flora of Costa Rica. Field Mus. Nat. Hist. Bot. Ser. 18(1-4).

Stebbins, R. C. 1944. Field notes on a lizard, the mountain swift, with special reference to territorial behavior. Ecology 25: 233-245.

Stebbins, R. D., \& R. M. Eakin. 1958. The role of the "third eye" in reptilian behavior. Amer. Mus. Novitates No. $1870: 1-40$.

Stoudemire, S. A. 1959. Natural history of the west Indies. Chapel Hill: Univ. North Carolina Press. 140 pp. (Translation of De la natural hystoria de las Indias. by Gonzalo Fernández de oviedo. 1526. Remón de Petras, Toledo) . 
Stuart, L. C. 1950. A geographic study of the herpetofauna of Alta Verapaz, Guatemala. Contrib. Lab. Vert. Biol. Univ. Mich. No. 45: 1-77.

Taylor, E. H. 1956. A review of the lizards of Costa Rica. Univ. Kansas Sci. Bull. 38: 3-222.

Tevis, L. Jr. 1944. Herpetological notes from Lower California. Copeia (1): 6-18.

Vogt, W. 1941. A practical lizard trap. Copeia (2): 115. Waugh, A. E. 1952. Elements of statistical method. 3 rd. ed. New York: McGraw-Hill Book Co., Inc. 531 pp. Wilhoft, D. C. 1958. The effect of temperature on the thyroid histology and survival in the lizard, Sceloporus occidentalis. Copeia (4): 265-275. - 1961. Temperature responses in two tropical Australian skinks. Herpetologica 17: 109-113. 


\section{BIOGRAPHICAL SKETCH}

Harold Frederick Hirth was born December 6, 1932, at Rockville, connecticut. In June, 1950, he graduated from Rockville High School. He received the degree Bachelor of Arts with High Honors from the University of Connecticut in June, 1954. From July, 1954, to November, 1956, he served in the United States Axmy and was honorably discharged with the rank of First Lieutenant. In June, 1958, he received the degree Master of science from the University of Connecticut. From september, 1958, unt11 the present time he has pursued work toward the degree Doctor of Philosophy at the University of Florida.

He 1 s a member of Phi Kappa Phi, Gamma Chi Epsilon, Society of the sigma Xi, Phi sigma society, Ecological Soclety of America, and the American Society of Mammalogists. 
This dissertation was prepared under the direction of the chairman of the candidate's supervisory committee and has been approved by all members of that committee. It was submitted to the Dean of the College of Arts and sciences and to the Graduate council and was approved as partial furlfillment of the requirements for the degree Doctor of Philosophy.

June 11, 1962

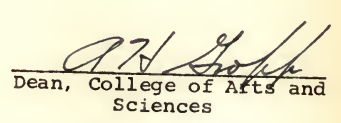

Supervisory Committee:

Dean, Graduate School
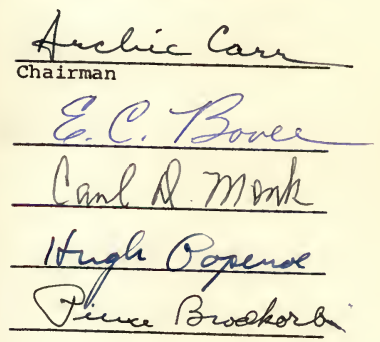